\title{
Prebiotic Chemistry and the Origin of the RNA World
}

\author{
Leslie E. Orgel
}

The Salk Institute, La Jolla, California, USA

The demonstration that ribosomal peptide synthesis is a ribozyme-catalyzed reaction makes it almost certain that there was once an RNA World. The central problem for origin-of-life studies, therefore, is to understand how a protein-free RNA World became established on the primitive Earth. We first review the literature on the prebiotic synthesis of the nucleotides, the nonenzymatic synthesis and copying of polynucleotides, and the selection of ribozyme catalysts of a kind that might have facilitated polynucleotide replication. This leads to a brief outline of the Molecular Biologists' Dream, an optimistic scenario for the origin of the RNA World. In the second part of the review we point out the many unresolved problems presented by the Molecular Biologists' Dream. This in turn leads to a discussion of genetic systems simpler than RNA that might have "invented" RNA. Finally, we review studies of prebiotic membrane formation.

Keywords nucleotide synthesis, polynucleotide formation, RNA replication, prebiotic membranes

\section{INTRODUCTION}

The ideas behind the hypothesis of an RNA World originated in the late 1960s in response to a profound puzzle. The basic principles of molecular biology were well understood, and it was clear that the replication of nucleic acids was dependent on protein enzymes and the synthesis of protein enzymes was dependent on nucleic acids. Even if one allowed for every possible simplification of the system, for example, by postulating a nucleic acid with only two bases and proteins assembled from a very limited suite of amino acids, what remained was too complicated to have arisen de novo from an assembly of abiotic organic molecules. The only way out was to regard the dilemma as

Editor: Michael M. Cox.

Address correspondence to Leslie E. Orgel, The Salk Institute, 10010 N. Torrey Pines Road, La Jolla, CA 92037, USA. E-mail: orgel@ salk.edu

a "chicken and egg problem" and to ask which came first, proteins or nucleic acids? At the time, it was well recognized that natural selection through replication and mutation was the only mechanism for evolving complex biochemical systems from simpler ones. Trying to solve the "chicken and egg" problem, therefore, was equivalent to asking whether proteins or nucleic acids were more plausible as the components of a self-contained replicating system. The answer seemed obvious: nucleic acids. WatsonCrick base-pairing provided a very plausible mechanism by which a polynucleotide could direct the synthesis of its complement from mononucleotides or short oligonucleotides, while no equivalent mechanism was known for the replication of a polypeptide. These arguments were developed in some detail in three overlapping papers (Woese, 1967; Crick, 1968; Orgel, 1968), and a program to explore nonenzymatic copying of nucleic acid sequences was initiated (Sulston et al., 1968a, 1968b).

The authors of the three early papers clearly recognized that an autonomous RNA "organism" would be possible only if RNA could take on several of the functions presently performed by proteins, for example, the functions of RNA polymerases and nucleases. They speculated that coenzymes incorporating nucleotides in their structure were fossils from a time when RNA functioned without the help of proteins (Woese, 1967; Orgel, 1968; Orgel \& Sulston, 1971), an idea that was subsequently developed in some detail (White, 1976). In one instance it was speculated that the original ribosome was composed entirely of RNA (Crick, 1968). However, in none of the papers was it suggested that RNA catalysis was still important in contemporary biology. It was taken for granted that protein enzymes could always outperform RNA catalysts and had, therefore, completely replaced them in contemporary organisms.

The unanticipated discovery of catalytic RNA molecules, ribozymes, that perform enzyme-like reactions (Kruger et al., 1982; Guerrier-Takada et al., 1983) marked the beginning of the present interest in a proteinless biological world. In the few years following Cech and Altman's discoveries, ribozymes were shown to be able to catalyze 
a significant number of diverse chemical reactions. This led to an increased interest in the hypothesis that an RNA World, a term introduced by Gilbert (Gilbert, 1986), preceded the DNA/RNA/Protein world (Gesteland et al., 1999). The determination of the structure of the ribosome, showing that it is a ribozyme (Steitz \& Moore, 2003), seems to clinch the case for an RNA World, although it leaves open almost all questions about the origin and "biochemistry" of the RNA World. The RNA World hypothesis does not deny that peptides may have been involved in the origin of life. It does, however, exclude the possibility that any peptides that were involved were formed by ribosomal protein synthesis or a closely related mechanism.

The knowledge that an RNA World preceded our familiar biochemical world has profound implications for those interested in the origin of life. It may be claimed, without too much exaggeration, that the problem of the origin of life is the problem of the origin of the RNA World, and that everything that followed is in the domain of natural selection. If this is accepted, studies of the chemistry of the origin of life are, in principle, greatly simplified because they need only be concerned with the origin of RNA and do not need to deal with the origins of most other features of biochemistry. Of course, the origin of protein synthesis and of DNA are also of the greatest interest, but their appearance can be regarded as the consequences of selection acting on populations of autonomous RNA organisms. The focus of this review, therefore, will be the origin of the RNA World and its evolution prior to the development of protein synthesis. We will have little to say about the prebiotic synthesis of amino acids, peptides, cofactors, etc.

While acceptance of an RNA World greatly simplifies the problem of the origin of life, it also has a negative aspect (Orgel, 2003). If the origin of the RNA World preceded the origin of protein synthesis, little can be learned about the chemistry of the origin of life from the study of protein enzyme mechanisms. The justification of prebiotic syntheses by appealing to their similarity to enzymatic mechanisms has been routine in the literature of prebiotic chemistry. Acceptance of the RNA World hypothesis invalidates this type of argument. If the RNA World originated de novo on the primitive Earth, it erects an almost opaque barrier between biochemistry and prebiotic chemistry.

It is possible that the RNA World was the first organized biochemical world on the primitive Earth. If we suppose that this is the case, the problem of the origin of life can conveniently be divided into a number of subproblems:

1. The nonenzymatic synthesis of nucleotides.

2. The nonenzymatic polymerization of nucleotides to give random-sequence RNA.

3. The nonenzymatic copying or replication or both, of RNA.
4. The emergence through natural selection of a set of functional RNA catalysts that together could sustain exponential growth in the prebiotic environment.

The first three topics are part of the traditional field of prebiotic chemistry, while the fourth is the subject matter of the newer field of RNA evolution. We begin this review by covering the first three topics in some detail. Since the fourth topic falls outside the scope of traditional prebiotic chemistry, only a very brief overview will be given. From our discussion of prebiotic chemistry we will conclude that the abiotic synthesis of RNA is so difficult that it is unclear that the RNA World could have evolved de novo on the primitive Earth, a conclusion that was first emphasized by Cairns-Smith (Cairns-Smith \& Davies, 1977; Cairns-Smith, 1982). Consequently, we will have to consider different routes to the RNA World. We will explore the possibility that a simpler replicating molecule could have formed on the primitive Earth and that organisms with a genetic system based on that simpler polymer could have "invented" RNA.

\section{PREBIOTIC SYNTHESIS OF NUCLEOTIDES}

\section{Prebiotic Synthesis}

Prebiotic chemistry is concerned with molecules that are interesting to students of the origin of life which, they believe, could have been formed on the primitive Earth. Since we know very little about the availability of starting materials on the primitive Earth or about the physical conditions at the site where life began, it is often difficult to decide whether or not a synthesis is plausibly prebiotic. Not surprisingly, claims of the type, "My synthesis is more prebiotic than yours" are common. Nonetheless, there is fairly general agreement about the following restrictions on organic synthesis imposed by the requirement for prebioticity:

It must be plausible, at least to the proposers of a prebiotic synthesis, that the starting materials for a synthesis could have been present in adequate amounts at the site of synthesis.

Reactions must occur in water or in the absence of a solvent.

The yield of the product must be "significant," at least in the view of the proposers of the synthesis.

Clearly "prebiotic" is a very elastic term, and it would not be wise to try to define it too closely.

Just as many people have been speaking prose all their lives without realizing it, many organic chemists of the 19th and the first half of the 20th century were prebiotic chemists without realizing it. If it were discovered for the first time today, Wohler's synthesis of urea from ammonium cyanate (Wohler, 1828) would certainly merit 
publication in Science or Nature as an important contribution to prebiotic chemistry. Butlerow's synthesis of sugars from formaldehyde (Butlerow, 1861) is still one of the cornerstones of the subject. However, these and other early experiments on the synthesis of biochemicals from simple starting materials were never motivated by an interest in the origin of life. Stanley Miller's classic experiment demonstrating the synthesis of amino acids in an electric discharge (Miller, 1953) marks the beginning of prebiotic chemistry as an enterprise directed to understanding the chemistry of the origin of life.

Miller and Urey believed that the atmosphere of the primitive Earth was strongly reducing, containing large amounts of methane and ammonia. Miller showed that formaldehyde and hydrogen cyanide ( $\mathrm{HCN})$ were key intermediates in the synthesis of glycine from such a mixture (Miller, 1957). Although not directly relevant to the origin of the RNA World, these observations led Juan Oro and his coworkers to study the products formed when ammonium cyanide is refluxed in aqueous solution. His remarkable discovery that adenine is a product of cyanide polymerization (Oro \& Kimball, 1960), together with the earlier results reported by Butlerow and Miller, determined the direction of research on prebiotic chemistry for many years. The relevance of all of this early work to the origin of life has been questioned because it now seems very unlikely that the Earth's atmosphere was ever as strongly reducing as Miller and Urey assumed. However, it still seems possible that that the Earth's atmosphere was once sufficiently reducing to have supported Miller/Urey chemistry to some extent (Kasting \& Brown, 1998).

\section{The Butlerow (Formose) Synthesis of Sugars from Formaldehyde}

The polymerization of formaldehyde in the presence of simple mineral catalysts to form a mixture of sugarsthe formose reaction - originally discovered by Butlerow in the 19th century (Butlerow, 1861), has been investigated in considerable detail (Mizuno \& Weiss, 1974). The reaction is of great interest as a unique, cyclic autocatalytic process that takes place in aqueous solution and converts a very simple substrate, formaldehyde, to a mixture of complex molecules, many of which are important biochemicals.

It is fortunate that Butlerow did not completely purify the formaldehyde he used before initiating the reaction, because the formation of sugars from formaldehyde is dependent on the presence of trace amounts of one of a number of common impurities (Socha et al., 1980; Kieboom \& VanBekkum, 1984). Glycolaldehyde, the first product of the polymerization reaction, is an efficient initiator and is often used in this role. In the absence of an initiator, formaldehyde in alkaline solution undergoes the Cannizaro reaction, yielding methanol and formic acid. The Butlerow synthesis of sugars is usually carried out in alkaline solution in the presence of a catalyst. Most studies have employed heterogeneous catalysts, particularly suspensions of calcium hydroxide, but some homogeneous catalysts are known, for example, $\mathrm{Pb}^{++}$and $\mathrm{Tl}^{+}$ions. A few investigations of the reaction under near-neutral conditions in the presence of minerals have been reported (Gabel \& Ponnamperuma, 1967; Reid \& Orgel, 1967).

The most intriguing feature of the formose reaction is the long induction period that precedes the formation of detectable products. Under many conditions the polymerization, once started, is completed in a time shorter than the induction period, but the induction period can be reduced progressively by adding increasing amounts of an initiator. The first product of the polymerization is glycolaldehyde, which is later converted to glyceraldehyde and a variety of tetrose, pentose, and hexose sugars. Under the conditions usually used to bring about the reaction, the sugars decompose to hydroxy-acids and related compounds on a timescale similar to that of their appearance.

Cycles of the type shown in Figure 1 best explain most of the experimental findings (Breslow, 1959). Two types of reaction are involved, forward and reverse aldol reactions and tautomerizations that interconvert aldehydes and ketones. The scheme in the figure is no doubt a gross oversimplification. Many related cycles involving reverse aldol reactions of different representatives of the tetrose, pentose, and hexose sugars must contribute to the total reaction. Furthermore, the addition of formaldehyde to glyceraldehyde and similar molecules leads to the formation of branched chain sugars, and the Cannizaro reduction of sugars to polyols is also an important side reaction (Mizuno \& Weiss, 1974). Despite these complications, the major conclusion to be drawn from the scheme in Figure 1 is correct;

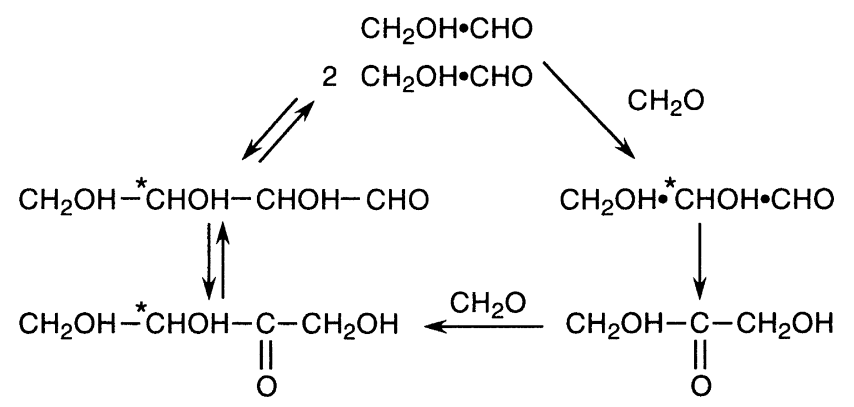

FIG. 1. The simplest hypothetical autocatalytic formose reaction cycle. In each turn of the cycle, a glycolaldehyde molecule facilitates the synthesis of a second glycolaldehyde molecule from two formaldehyde molecules. The stereochemistry at the asymmetric carbon atoms (marked with asterisks in the diagram) is not specified. 
as the consequence of traversing a cycle of the type shown, a single input glycolaldehyde molecule leads, in principle, to the production of two output glycolaldehyde molecules. This ensures an exponentially growing rate of product formation until the concentration of formaldehyde begins to decline.

The Butlerow reaction, if it could be directed to the synthesis of ribose, would provide an ideal route to the sugar component of the nucleotides. However, until recently it had not been possible to channel the Butlerow reaction to the synthesis of any particular sugar, and ribose usually has been a notoriously minor product (Decker et al., 1982). More recently, Zubay has studied in detail the progress of the $\mathrm{Pb}^{++}$catalyzed formose reaction (Zubay, 1998; Zubay $\&$ Mui, 2001). He has shown that more than $30 \%$ of the input formaldehyde can be converted to a mixture of the aldopentoses and provides evidence suggesting that ribose is the first pentose sugar formed, and that the other pentoses are formed from it by $\mathrm{Pb}^{++}$-catalyzed isomerization. These studies suggest that a satisfactory prebiotic synthesis of ribose may be possible. In a very recent report it has been claimed that the four pentose sugars are stabilized by the presence of calcium borate minerals (Ricardo et al., 2004).

The production of ribose in the formose reaction depends, at least in part, on the aldol reaction of glycolaldehyde with glyceraldehyde. Eschenmoser and his coworkers showed that the pattern of products could be greatly simplified if glycolaldehyde and glyceraldehyde were replaced by their monophosphates (Mueller et al., 1990). Under alkaline conditions glycolaldehyde phosphate alone yields a relatively simple mixture of tetrose-2-4diphosphates and hexose-2-4-6-triphosphates. Most interestingly, ribose-2-4-diphosphate was the major sugar product from the reaction of glycolaldehyde phosphate with glyceraldehyde-2-phosphate. Ribose-2-4diphosphate was also a major product of an equivalent reaction involving formaldehyde and two molecules of glycolaldehyde-phosphate. In these reactions the phosphate groups prevent the rearrangements that are characteristic of triose, tetrose, and pentose sugars under alkaline conditions and that lead directly or indirectly to much of the complexity of the formose product mixture. Eschenmoser's synthesis would provide a first step in a plausible route to the nucleotides if ribose-2-4-diphosphate could be converted to a 5-phosphate or a 1-5-diphosphate.

The reactions described above occur in solution only at high $\mathrm{pHs}$ and with high concentrations of the reactants. However, certain layer hydroxides such as magnesium aluminium hydroxide are powerful catalysts for the reaction. Negatively charged organic phosphates are absorbed so strongly between the positively charged metal-hydroxide layers that they can be concentrated from very dilute solution. Furthermore, once in the environment between the metal-hydroxide layers, they react rapidly to form sugar phosphates even if the $\mathrm{pH}$ of the external solution is close to 7 (Pitsch et al., 1995). Since layer hydroxides are abundant minerals, this version of Eschenmoser's synthesis may be considered as a promising prebiotic reaction. However, it is less specific than the solution reaction for the production of ribose-2-4-diphosphate.

We conclude that some progress has been made in the search for an efficient and specific prebiotic synthesis of ribose and its phosphates. However, in every scenario, there are still a number of obstacles to the completion of a synthesis that yields significant amounts of sufficiently pure ribose in a form that could readily be incorporated into nucleotides.

\section{Purine Synthesis}

In a series of seminal papers published in the 1950s, Juan Oro and his coworkers showed that adenine is produced in appreciable yield by refluxing a solution of ammonium cyanide, and that 4-amino-5-cyanoimidazole (II) is an intermediate in the synthesis (Oro \& Kimball, 1960, 1961, 1962; Oro, 1961a). This and closely related reactions have been investigated repeatedly under different reaction conditions, and the products have been analyzed using improved analytical techniques. In addition to adenine, small amounts of guanine have been detected among the products of HCN polymerization (Miyakawa et al., 2002a, 2002b). In a particularly striking experiment, adenine has been obtained in $20 \%$ yield by heating $\mathrm{HCN}$ with liquid ammonia in a sealed tube (Wakamatsu et al., 1966). Here we can only review the literature on $\mathrm{HCN}$ polymerization that is most relevant to prebiotic chemistry.

The first reasonably stable product of the polymerization of $\mathrm{HCN}$ in aqueous solution is the HCN tetramer, diaminomaleodinitrile (I). Subsequent steps in the polymerization are complex and are not well understood. The tetramer, once formed, initiates a further polymerization reaction that leads to the precipitation of a dark intractable solid from which adenine, guanine, and numerous other mostly uncharacterized compounds can be released by hydrolysis with acids or bases. In some experiments a small quantity of adenine is also present in the solution phase (Miyakawa et al., 2002a, 2002b). Very little is known about the structure of the insoluble polymer or about the way in which adenine is incorporated into it. While some adenine may be released directly from the solid on hydrolysis by acid, much of it is released initially as adenine-8carboxamide and related compounds (Voet \& Schwartz, 1983).

Several reactions that might contribute to the synthesis of adenine from $\mathrm{HCN}$ via the $\mathrm{HCN}$ tetramer (Figure 2) have been studied (Ferris \& Orgel, 1965, 1966a; Sanchez et al., 1967, 1968). It has been shown that 
(a)

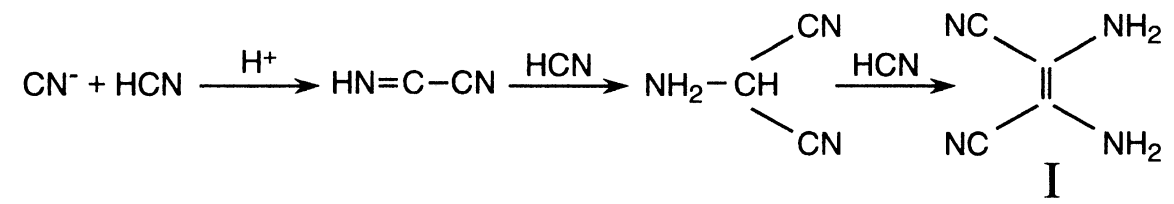

(b)

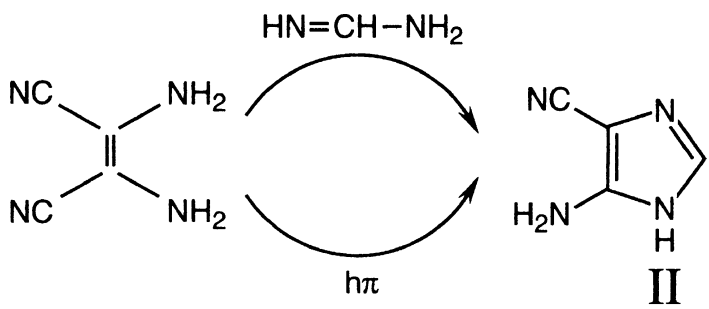

(c)

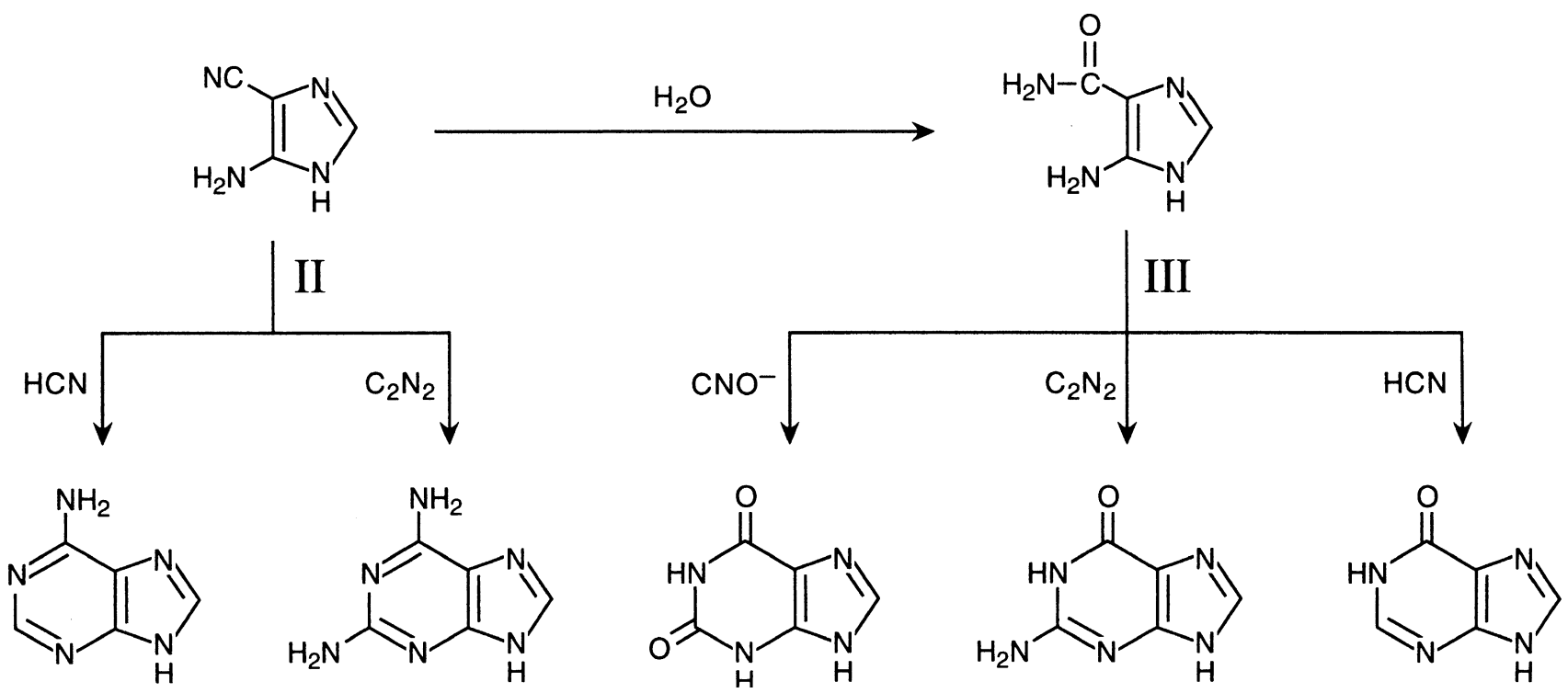

FIG. 2. Steps in possible prebiotic syntheses of adenine from HCN. (a) The formation of the HCN tetramer. (b) The conversion of HCN tetramer to AICN. (c) The formation of purines from AICN or from its hydrolysis product 4-amino-imidazole-5-carboxamide (III).

formamidine can be formed by the addition of ammonia to $\mathrm{HCN}$, and that formamidine reacts with the $\mathrm{HCN}$ tetramer to give 4-amino-5-cyano-imidazole (AICN) (Figure 2b), which, in turn, reacts with a second molecule of formamidine to yield adenine. In other experiments it has been shown that $\mathrm{HCN}$ adds to $\mathrm{AICN}$ in aqueous solution to give adenine directly (Figure 2c). Heating HCN tetramer or AICN with ammonium formate- the hydrolysis product of $\mathrm{HCN}$ - in the solid state is another way of obtaining adenine (Zubay \& Mui, 2001; Hill \& Orgel, 2002). Adenine has also been obtained directly by heating formamide, a synthesis that may involve $\mathrm{HCN}$ as an intermediate (Saladino et al., 2001). However, none of the reactions has been proven to contribute directly to adenine synthesis under the conditions employed by Oro and his coworkers.
AICN and its hydrolysis product 4-amino-imidazole-5carboxamide (III) are readily converted to hypoxanthine and a variety of 2,6-disubstituted purines in aqueous solution by reaction with simple one-carbon molecules (Figure 2c) (Sanchez et al., 1968). Thus AICN and the related carboxamide, if they could be obtained under prebiotic conditions, would offer very plausible routes to the purines that are important in biochemistry. We must therefore review attempts to obtain $\mathrm{HCN}$ tetramer and to convert it to AICN under plausibly prebiotic conditions.

Detailed kinetic studies show that hydrolysis of $\mathrm{HCN}$ to formamide and ultimately ammonium formate competes very effectively with tetramer synthesis if the $\mathrm{HCN}$ concentration falls below $10^{-1}$ to $10^{-2} \mathrm{M}$ (Sanchez et al., 1967). It would have been impossible to reach such a high concentration of $\mathrm{HCN}$ in the bulk oceans, while 
evaporation of lakes or tide pools could not adequately concentrate a molecule as volatile as $\mathrm{HCN}$. The most plausible prebiotic method for concentrating HCN is by "eutectic freezing" (Sanchez et al., 1966a). If a dilute aqueous solution of $\mathrm{HCN}$ is cooled below $0^{\circ} \mathrm{C}$, pure ice crystallizes out and the solution becomes more concentrated until a eutectic is obtained at $-23.4^{\circ} \mathrm{C}$ that contains 74.5 (moles)\% of HCN. This very concentrated solution slowly deposits a typical dark HCN polymer. Schwartz and his coworkers showed that adenine could be obtained in $0.004 \%$ yield by hydrolysis of this polymer or in $0.02 \%$ yield if glycolonitrile was added to the reaction mixture before freezing (Schwartz et al., 1982). Miller and his coworkers have obtained very similar results (Miyakawa et al., 2002a, $2002 \mathrm{~b}$ ). At present, the most plausible routes to adenine from $\mathrm{HCN}$ involve an initial synthesis of $\mathrm{HCN}$ tetramer in solutions concentrated by freezing.

The route from $\mathrm{HCN}$ tetramer to AICN by reaction with formamidine (Figure $2 \mathrm{~b}$ ) is somewhat problematical, since the formation of formamidine would require a high concentration of ammonia, and it is questionable that ammonia was ever present on the primitive Earth in significant amounts. The photochemical isomerization of the $\mathrm{HCN}$ tetramer (Figure $2 \mathrm{~b}$ ) provides an alternative route to AICN (Ferris \& Orgel, 1966b). The reaction occurs readily in sunlight and gives almost quantitative yields of AICN. The combination of $\mathrm{HCN}$ tetramer formation in eutectic solution (Figure 2a), photoisomerization of tetramer to AICN (Figure 2b), and reaction of AICN with $\mathrm{HCN}$ to give adenine (Figure 2c) constitutes a potentially prebiotic synthesis of adenine that is independent of ammonia.

Completely different schemes for the accumulation of adenine and other purines on the primitive Earth have been discussed. Miyakama and his coworkers suggested that purines were formed in the atmosphere but by mechanisms that are independent of HCN (Miyakawa et al., 2000). Substantial amounts of adenine have been found in carbonaceous chondrites, so it has been suggested that purines were formed elsewhere in the solar system, perhaps by Oro-type chemistry, and brought to the Earth in meteorites (Oro, 1961b; Chyba \& Sagan, 1992).

\section{Pyrimidine Synthesis}

Most of the published work on prebiotic pyrimidine synthesis is concerned with a series of closely related reactions between cyanoacetylene (IV) or its hydrolysis product, cyanoacetaldehyde (V), and cyanate ions, cyanogen or urea (Figure 3) (Ferris et al., 1968, 1974; Robertson \& Miller, 1995a, 1995b; Nelson et al., 2001). The product, cytosine, is obtained in good yield in several of these reactions. Since cyanoacetylene is a major product formed when an electric discharge is passed through a mixture of nitrogen and methane (Sanchez et al., 1966b) and hy- drolyses readily to cyanoacetaldehyde (Ferris et al., 1968), these two molecules have been claimed to be potentially prebiotic (Orgel, 2002). Uracil is formed from cytosine by hydrolysis, and this has been proposed as a prebiotic synthesis.

The highest yields of cytosine, up to $50 \%$, are obtained when cyanoacetaldehyde is incubated with a saturated solution of urea (Robertson \& Miller, 1995a, 1995b). However, the so-called drying lagoon model, which postulates that lagoons of saturated urea existed on the primitive Earth does not seem plausible (Shapiro, 1999, 2002). More modest yields of cytosine (about 5\%) are obtained when cyanoacetylene reacts with $1.0 \mathrm{M}$ cyanate or when either cyanoacetylene or cyanoacetaldehyde reacts with 1.0 M urea (Ferris et al., 1968; Robertson \& Miller, 1995a, $1995 \mathrm{~b})$. The reactions of cyanoacetylene or cyanoacetaldehyde with urea or of cyanoacetylene with cyanate in eutectic solution seem the most plausible prebiotic routes to cytosine. Syntheses of this kind are particularly attractive because they could proceed in parallel with the synthesis of adenine from HCN (Orgel, 2004).

\section{Nucleoside Synthesis}

The synthesis of nucleosides from ribose and the nucleoside bases is the weakest link in the chain of prebiotic

(a)

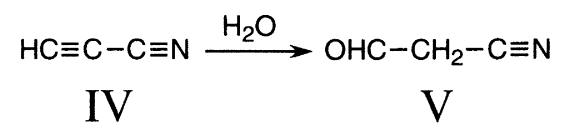

(b)

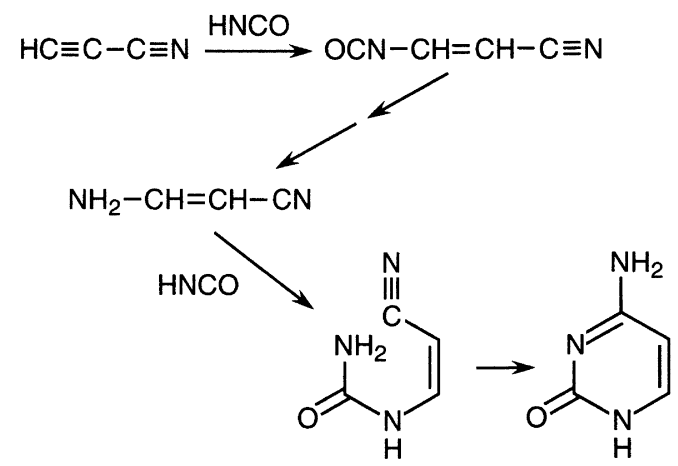

(c)

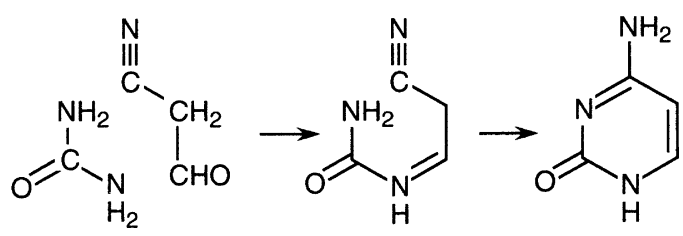

FIG. 3. Steps in proposed prebiotic syntheses of cytosine. (a) The hydrolysis of cyanoacetylene to cyanoacetaldehyde. (b) The reaction between cyanoacetylene and two molecules of cyanic acid. (c) The condensation of cyanoacetaldehyde with urea. 


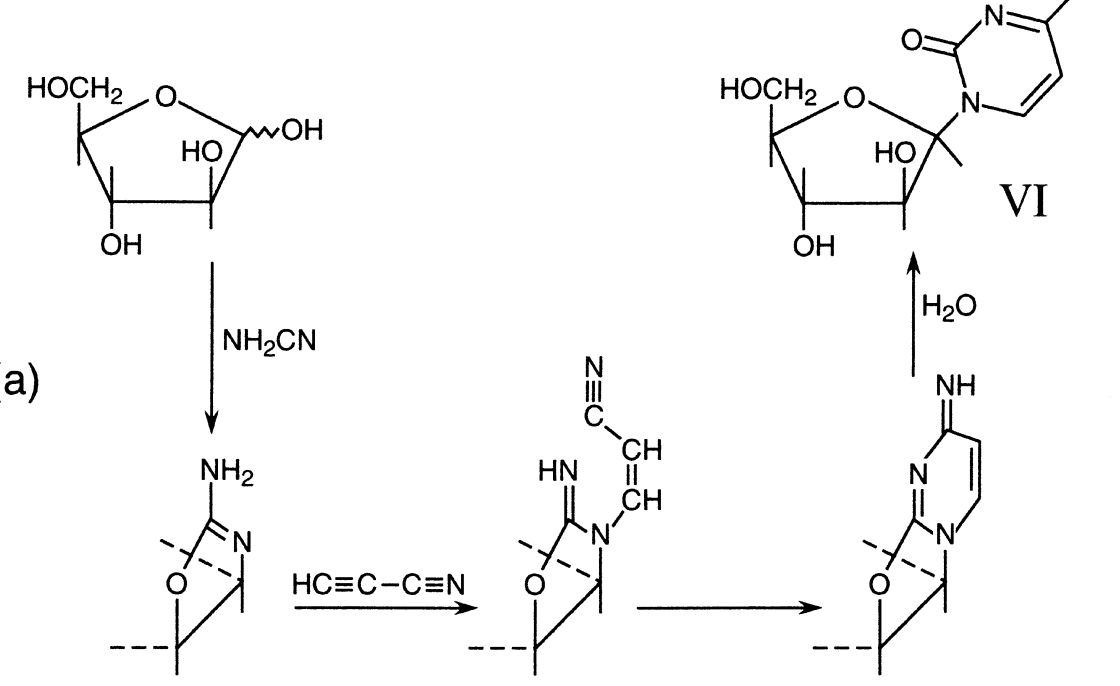

(b)
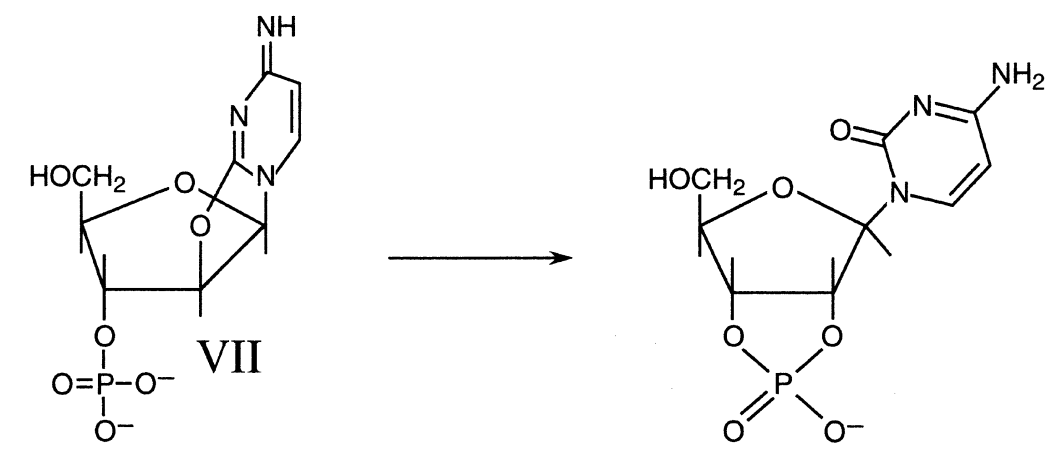

FIG. 4. (a) The synthesis of cytosine arabinoside from arabinose, cyanamide, and cyanoacetylene. (b) Modification of the mode of hydrolysis of cyclocytidine caused by the presence of a neighboring phosphate group.

reactions leading to oligonucleotides. If D-ribose is heated directly with hypoxanthine in the presence either of magnesium chloride or of the mixture of inorganic salts present in seawater, up to $8 \%$ of authentic $\beta$-D-inosine is formed, along with a somewhat smaller amount of the $\alpha$-isomer (Fuller et al., 1972). The product mixture formed from adenine under the same conditions is more complex, since the major reaction occurs at the amino-group of the base, and nucleoside formation is a relatively minor side reaction. However, hydrolysis of the reaction products under relatively mild conditions leaves behind a small yield of a mixture of adenosine isomers including up to $3 \%$ of $\beta$-Dadenosine.

No direct synthesis of pyrimidine nucleosides from ribose and uracil or cytosine has been reported. An indirect synthesis in which $\alpha$-cytidine is first obtained from ribose, cyanamide, and cyanoacetylene in aqueous solution has been described (Sanchez \& Orgel, 1970). The correspond- ing reaction of arabinose yields $\beta$-cytosine arabinoside (VI) (Figure 4a). If ribose is replaced by ribose-5-phosphate in this reaction sequence $\alpha$-cytidine$5^{\prime}$-phosphate is obtained in up to $40 \%$ yield. It is possible to photo-anomerize $\alpha$-cytidine to $\beta$-cytidine but only in 5\% yield (Sanchez \& Orgel, 1970). A similar reaction occurs with a $\alpha$-cytidine- $5^{\prime}$-phosphate.

Nagivary prepared the 3 -phosphate of cyclo-cytidine (VII) by standard laboratory synthesis and showed that it hydrolyzes in water, via a cyclic phosphate, to give a good yield of cytidine $2^{\prime}\left(3^{\prime}\right)$-phosphate (Figure $4 \mathrm{~b}$ ) along with a smaller amount of cytosine arabinoside-3'-phosphate. He speculated that these two reactions together might provide a prebiotic route to cytidine- 3 '-phosphate (Tapiero \& Nagyvary, 1971). More recently, Sutherland and his coworkers have succeeded in combining the two reaction sequences, thus obtaining cytidine- $3^{\prime}$-phosphate directly, in aqueous solution, from arabinose-3-phosphate, 
cyanamide and cyanoacetylene (Ingar et al., 2003). The source of arabinose 3-phosphate on the primitive Earth is unclear, but this work nonetheless suggests that the prebiotic synthesis of pyrimidine nucleotides may be possible.

One mode of biosynthesis of nucleosides or nucleotides involves the displacement of phosphate from $\alpha$-ribose1-phosphate or of pyrophosphate from $\alpha$-ribose-5phosphate-1-pyrophosphate by a nucleoside base. This seems to provide a promising approach to the corresponding prebiotic syntheses. A few preliminary and unpublished experiments attempted in our laboratory using ribose 1-phosphate were unsuccessful, but preliminary experiments reported by Zubay and his coworkers suggest that a synthesis from ribose-5-phosphate-1-pyrophosphate may be possible (Zubay \& Mui, 2001).

\section{Phosphorylation of Nucleosides}

Inorganic phosphates or polyphosphates are the most plausible source of phosphate for prebiotic synthesis, although reduced forms of phosphorus have occasionally been considered in this context (Schwartz, 1997; Peyser \& Ferris, 2001). Only orthophosphates are abundant in rocks and minerals, principally insoluble calcium phosphates, but there is evidence that condensed phosphates are products of volcanism (Yamagata et al., 1991). A number of approaches to prebiotic synthesis using inorganic orthophosphates or polyphosphates have been explored.

Many of the earliest attempts to phosphorylate nucleosides utilized organic condensing agents such as cyanamide, cyanamide dimer, or cyanate. These reactions are prebiotic equivalents of the much-used phosphorylation protocols that employ carbodiimides as activating agents in organic solvents. Unfortunately, such reactions are usually inefficient in aqueous solution because of the competition of water for the activated phosphate intermediate (Lohrmann \& Orgel, 1968). Appreciable yields of cyclic phosphates can occasionally be obtained, for example, from monophosphates of cis glycols, because the cis hydroxyl group can compete efficiently with water for the activated phosphate moiety. Nucleoside- $2^{\prime}-$ or $3^{\prime}$-phosphates sometimes give nucleoside-2'- or $3^{\prime}$-cyclic phosphates in good yield in this way. More recently it has been shown that AMP can be converted to ADP and ATP by cyanate in the presence of insoluble calcium phosphates (Yamagata, 1999).

Nucleosides, like other alcohols, can be phosphorylated by heating in the solid state with acidic phosphates such as $\mathrm{NaH}_{2} \mathrm{PO}_{4}$. These reactions require fairly high temperatures and are not very efficient (Beck et al., 1967). However, urea, and to a lesser extent amides such as acetamide, catalyze the reaction, particularly if ammonium phosphate is used as the inorganic component. Presumably, ammo- nium phosphate is particularly effective in this reaction because it loses ammonia on heating and thus generates a very acidic environment. In the absence of an organic component, heating ammonium phosphate with urea yields a mixture of high molecular-weight linear polyphosphates (Lundstrom \& Whittaker, 1937; Osterberg \& Orgel, 1972).

Nucleosides can be converted to a complex mixture of products containing one or more phosphate groups in excellent yield by heating at moderate temperatures with ammonium phosphate and urea (Lohrmann \& Orgel, 1971). When uridine, for example, is heated with excess urea and ammonium phosphate at $100^{\circ} \mathrm{C}$, about $70 \%$ of the input is converted to a complex mixture of phosphorylated products (Figure 5). Attempts to direct this reaction to the synthesis of a particular phosphate or polyphosphate, for example, a nucleoside- $5^{\prime}$-phosphate or $5^{\prime}$-triphosphate, have met with some success (Handschuh et al., 1973; Osterberg et al., 1973; Reimann \& Zubay, 1999). These solid-state reactions have been studied in considerable detail, but the reaction mechanism is not known. It is unlikely to involve carbamoyl phosphate or a phosphoramidate intermediate, so acid-base catalysis seems most probable (Osterberg \& Orgel, 1972).

Phosphorus is present on the Earth today almost entirely as insoluble calcium phosphates, and this is likely to have been true on the primitive Earth. The urea-catalyzed phosphorylation reaction discussed above proceeds much more slowly when ammonium phosphate is replaced by calcium phosphate. Nonetheless, yields of nucleotides as high as $20 \%$ were obtained when hydroxylapatite was heated

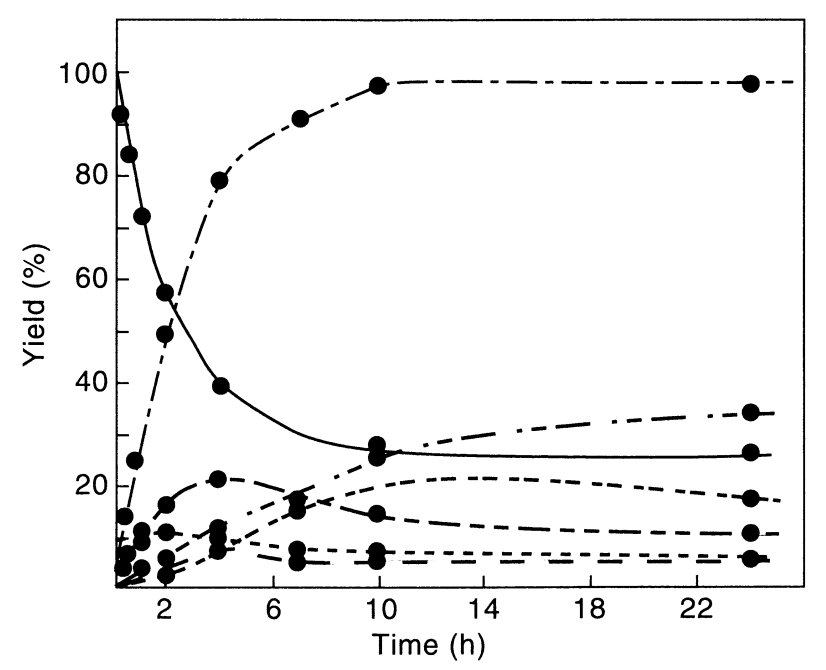

FIG. 5. Phosphorylation of uridine with a mixture of inorganic phosphate, ammonium chloride, ammonium bicarbonate, and urea at $100^{\circ} \mathrm{C}$. U, —; Up!, - - - —; pU, - - —; Up, - — — ; pUp!, - - —; pUp - - - - - ; total incorporation of inorganic phosphate, - Redrawn from Figure 6 in Lohrmann and Orgel (1971). 
with urea, ammonium chloride, and a nucleoside at $100^{\circ} \mathrm{C}$ (Lohrmann \& Orgel, 1971).

We have seen that the heating of ammonium phosphates with a catalyst such as urea leads to the formation of a mixture of linear polyphosphates. These compounds can also be formed by heating other acidic phosphates such as $\mathrm{NaH}_{2} \mathrm{PO}_{4}$ strongly and, perhaps for this reason, are produced in volcanoes (Yamagata et al., 1991). While linear polyphosphates have never been shown to be good phosphorylating agents in aqueous solution, they are converted readily to cyclic triphosphates, the trimetaphosphates, under alkaline conditions in the presence of divalent metal ions. The cyclic trimetaphosphates are important as potentially prebiotic phosphorylating agents.

Cis glycols react with trimetaphosphate in strongly alkaline solution to yield cyclic phosphates that subsequently hydrolyze readily to a mixture of monophosphates. Nucleosides yield $2^{\prime}, 3^{\prime}$-cyclic phosphates that hydroyze to a mixture of $2^{\prime}$ - and $3^{\prime}$-phosphates, often in excellent yield (Schwartz, 1969; Saffhill, 1970; Tsuhako et al., 1984). The same reaction occurs less efficiently under less alkaline conditions in the presence of $\mathrm{Mg}^{++}$(Yamagata et al., 1995) or in a cycle of wetting and drying reactions (Cheng et al., 2002). Monohydric alcohols react only under highly alkaline conditions to yield triphosphates, for ex- ample, a mixture of thymidine- $3^{\prime}$-triphosphate, thymidine$5^{\prime}$-triphosphate, and a small amount of thymidine $3^{\prime}-5^{\prime}$-bis triphosphate from thymidine (Etaix \& Orgel, 1978).

Amines react very readily with trimetaphosphate to give $N$-triphosphates. An ingenious modification of this reaction provides a simple procedure for phosphorylating 2-hydroxyaldehydes (Krishnamurthy et al., 2000). The reaction of ammonia with the trimetaphosphate anion yields an amidotriphosphate that can form a Schiff's base with the carbonyl group of the hydroxyaldehyde. Next the 2 -hydroxyl group attacks the $\alpha$-phosphate, expelling pyrophosphate and forming a cyclic phosphoramidate. Finally the cyclic phosphoramidate undergoes hydrolysis to yield the 2-phosphate of the aldehyde (Figure 6). This reaction sequence is of considerable interest for prebiotic chemistry because glycolaldehyde phosphate and glyceraldehydes-2-phosphate are important, potentially prebiotic molecules.

While most effort has been devoted to the phosphorylation of preformed nucleosides, the direct phosphorylation of ribose is also interesting because the reaction of $\alpha$-ribofuranose-1-phosphate with nucleoside bases is a plausible route to the nucleosides. Ribose can be phosphorylated directly with inorganic phosphate in aqueous solution using cyanogen or cyanamide as a condensing

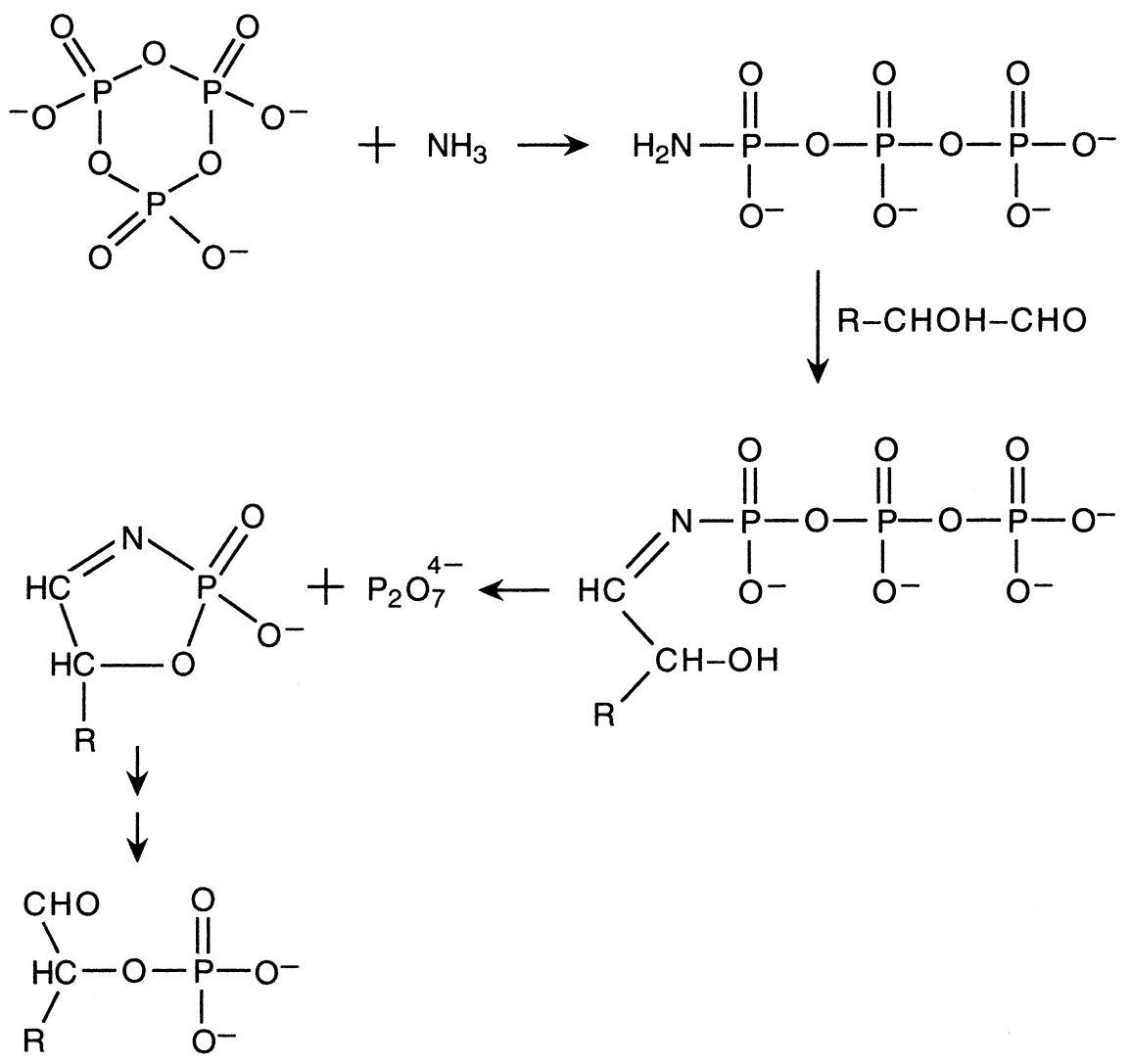

FIG. 6. The phosphorylation of $\alpha$-hydroxyaldehydes by the amidotriphosphate anion. 
agent (Halmann et al., 1969). The product, however, is relatively pure $\beta$-ribofuranose- 1 phosphate, not the desired $\alpha$-isomer.

\section{Conclusion}

The inevitable conclusion of this survey of nucleotide synthesis is that there is at present no convincing, prebiotic total synthesis of any of the nucleotides. Many individual steps that might have contributed to the formation of nucleotides on the primitive Earth have been demonstrated, but few of the reactions give high yields of products, and those that do tend to produce complex mixtures of products. It should also be realized that any prebiotic synthesis of a nucleotide would yield a racemic product, not the biologically important D-nucleotide. Recent publications, particularly those of Zubay and his coworkers (cited above), suggest that the search for a convincing prebiotic synthesis of the nucleotides is not hopeless. However, the difficulties remain so severe that alternatives to the de novo appearance of RNA on the primitive Earth deserve serious consideration. The succeeding sections of this review, in addition to discussing possible routes to RNA from a hypothetical source of prebiotic nucleotides, will also consider other ways in which the RNA World could have appeared.

\section{INPUT IN METEORITES OR COMETS}

A substantial proportion of the meteorites that presently fall on the Earth belong to a class known as carbonaceous chondrites. These interesting stones may contain more than $3 \%$ of carbon, much of it organic. Numerous detailed chemical analyses of carbonaceous chondrites have led to the identification of a very large number of hydrocarbons, carboxylic acids, amino acids, hydroxy acids, sulfonic acids, phosphonic acids, poly-hydroxy compounds (Cooper et al., 2001), etc. Very little is known in detail about the mechanisms that produced the various classes of molecules. It is thought that primary processes in the interstellar or stellar medium produced organic precursors that were incorporated into the parent bodies of the meteorites. Then further processing on the parent bodies modified and extended the inventory of organics. The details of this complex subject are beyond the scope of the present review. Comprehensive accounts of all aspects of this complicated chemistry are available (Anders, 1989; Chyba \& Sagan, 1992; Cronin \& Chang, 1993; Botta \& Bada, 2002). The presence of adenine and the other nucleoside bases in the carbonaceous chondrites at a level of about one part per million, however they may have formed, is obviously relevant to discussions of the origin of the RNA World.

There can be no doubt that material analogous to that making up the carbonaceous chondrites contribute substantially to the formation of the Earth, and that the influx of meteoritic material was much greater during the early history of the Earth than it is today. The extent to which the organic material present in meteorites could have survived passage through the atmosphere and impact on the surface of the Earth is unclear. It is also difficult to estimate the importance of micrometeorites and comets (Goo, 1961), which are thought by some to have brought in the bulk of the organic material that was present on the early Earth. Despite the uncertainties, many scientists believe that meteorites, comets, and interplanetary dust particles were the major source of organic material for the origin of life. If so, life must have originated in a mixture of organic molecules different from those obtained by Miller/Urey chemistry but at least as complicated.

\section{SYNTHESIS IN THE DEEP SEA VENTS}

Wachtershauser initiated a novel approach to the problem of the origin of life (Wachtershauser, 1988). He proposed that the original source of organic material for the origin of life was provided by the reduction of carbon dioxide using hydrogen sulfide $\left(\mathrm{H}_{2} \mathrm{~S}\right)$ over ferrous sulfide $(\mathrm{FeS})$ as the reducing agent. He further proposed that the products of this reaction never entered free aqueous solution but set up a complex "metabolism" while confined to the surface on which they were synthesized. In more detail, he noted that the conversion of $\mathrm{FeS}$ to $\mathrm{FeS}_{2}$, pyrite, by $\mathrm{H}_{2} \mathrm{~S}$ could provide the reducing power needed to produce organic material from $\mathrm{CO}_{2}$. The self-organization of the reductive citric acid cycle on an iron sulfide surface without the help of enzymes or other informational molecules was also a central part of his scheme. Chemistry of this kind could most plausibly occur in the deep-sea vents, where superheated water containing dissolved $\mathrm{H}_{2} \mathrm{~S}$ and transition-metal sulfides is mixed suddenly with a large excess of cold seawater, causing sulfides, including large amounts of FeS, to precipitate. Scenarios for the origin of life that involve this or related hydrothermal chemistry are now popular. As far as I am aware, these scenarios have not been shown to be directly relevant to the origin of the RNA World, but they may be relevant to the origin of membrane-forming organic material.

Wachtershauser's imaginative suggestion that the formation of $\mathrm{FeS}_{2}$ from $\mathrm{H}_{2} \mathrm{~S}$ and $\mathrm{FeS}$ could drive reduction has been amply confirmed in his collaborations with Stetter and his coworkers. They have, for example, demonstrated the reduction of acetylene and mercaptans by $\mathrm{H}_{2} \mathrm{~S}$ over FeS (Blochl et al., 1992). Most impressively, it has recently been reported that freshly precipitated ferrous sulfide in the presence of $\mathrm{H}_{2} \mathrm{~S}$ is able to reduce molecular nitrogen to ammonia (Dorr et al., 2003). Thus, the reaction of $\mathrm{FeS}$ with $\mathrm{H}_{2} \mathrm{~S}$ to form pyrite provides the driving 
force for many reductions, including the very difficult reduction of $\mathrm{N}_{2}$ to ammonia in just the way predicted by Wachtershauser.

The reduction of $\mathrm{CO}_{2}$ has not been achieved, but an interesting alternative synthesis, the reaction of carbon monoxide with methyl mercaptan over a mixed iron/nickel sulfide to give an activated derivative of acetic acid, probably the methyl thioester, has been described (Huber \& Wachtershauser, 1997). In another paper, Huber and Wachtershauser report that peptides are formed from amino acids by activation with carbon monoxide in the presence of $\mathrm{Fe} / \mathrm{Ni} \mathrm{S}$ and $\mathrm{H}_{2} \mathrm{~S}$ or methyl mercaptan (Huber \& Wachtershauser, 1998). They suggest that carbonyl sulfide may be an intermediate in this reaction, its hydrolysis to carbon dioxide and hydrogen sulfide in the presence of transition-metal sulfides providing the free energy needed to drive peptide synthesis. The $N$-carboxyanhydrides of the amino acids are probably intermediates in the reaction sequence.

Cody and his coworkers have reported another potentially important synthesis. They were able to obtain pyruvic acid from formic acid, a source of carbon monoxide, in the presence of nonylmercaptan and $\mathrm{FeS}$ (Cody et al., 2000). The reaction was carried out at $250^{\circ} \mathrm{C}$ and a high pressure, without the addition of water in excess of that generated by the decomposition of the formic acid. The synthesis of a significant yield of pyruvic acid, a relatively unstable molecule at such a high temperature, is unexpected. It is not clear whether nonylmercaptan has an essential role in the reaction or if it could be omitted or replaced by a lower molecular weight thiol such as methyl mercaptan, nor is it known whether the synthesis occurs entirely on the surface of $\mathrm{FeS}$ or if a volatile metal carbonyl is involved.

In addition to these recent studies, earlier work on the Fischer-Tropsch reaction, which leads to the production of long straight-chain hydrocarbons and their oxygenated derivatives from carbon monoxide and hydrogen in the presence of a suitable catalyst, may well be relevant to the chemistry of the deep-sea vents. The conditions and catalysts typically employed in the chemical industry are unlikely to have been present on the primitive Earth, but there is some evidence that similar results can be obtained with plausible prebiotic catalysts (Zolotov et al., 2001). The production of straight-chain fatty acids might provide a source of membrane-forming organic material (see below).

In the light of all of the experimental evidence, the deepsea vents must now be added to the list of plausible sources of some or all of the organic material needed for the origin of life. However, it seems unlikely that nucleotides could have formed directly in the vents, so Wachtershauser's theory is best suited to a scenario in which some other genetic polymer preceded RNA (see below).
In the above discussion I have treated reactions that occur on metal sulfides as prebiotic syntheses that support a novel scenario for the formation of the organic substrates that contributed to the origin of life. Wachtershauser insists that they are more than that and that they support his theory of a complex surface metabolism in which the reductive citric acid cycle or something like it self-organized on the surface of a metal sulfide. I am unaware of any experimental evidence for such self-organization, and I have argued elsewhere that on theoretical grounds it is exceedingly unlikely that such self-organization could occur (Orgel, 2000). If life originated in the deep-sea vents, I think it more likely that the vents provided the components of a relatively simple informational polymer. Unfortunately, the experimental study of hydrothermal reactions under anaerobic conditions requires the use of specialized equipment that is available in only a limited number of laboratories, so it may be a substantial time before the scope of hydrothermal synthesis on the surfaces of transition metal sulfides is adequately explored.

\section{POLYMERIZATION OF ACTIVATED NUCLEOTIDES}

The polymerization of nucleotides in aqueous solution is an uphill reaction and does not occur spontaneously to a significant extent. Evaporation of acidic solutions of nucleotides and subsequent heating leads to the formation of complex mixtures of very short oligonucleotides, in which $2^{\prime}-5^{\prime}$-, or $3^{\prime}-5^{\prime}$-phosphodiester linkages occur more or less at random (Moravek, 1967). Consequently, attempts to polymerize nucleotides from aqueous solution must necessarily make use of external activating agents. Attempts along these lines using cyanamide and similar activating agents or water-soluble carbodiimides have been disappointing, at best leading to poor yields of dinucleotides and very short oligonucleotides.

Polymerization of preactivated nucleotides has met with greater success. Unfortunately, nucleoside-5'-polyphosphates react so slowly in aqueous solution at moderate temperatures and $\mathrm{pHs}$ that their polymerization cannot easily be studied in the laboratory. Instead, nucleotides activated as phosphoramidates, usually phosphorimidazolides, have been used as substrates in most experiments (Figure 7a). They can be obtained in fairly good yield from nucleoside-5' -polyphosphates and amines or imidazoles and have, therefore, been claimed to be prebiotic (Lohrmann, 1977). However, it is unclear that phosphorimidazolides could have occurred in large amounts on the primitive Earth, so these experiments form only a rough guide to the classes of reaction that might have been relevant to chemical evolution. The source of the free energy needed to drive the uphill polymerization of nucleotides is unclear. One plausible suggestion involves the initial formation of nucleoside polyphosphates from nucleosides 
(a)<smiles>[B]C1OC(COP(=O)([O-])n2ccnc2)C(O)C1O</smiles>

VIII

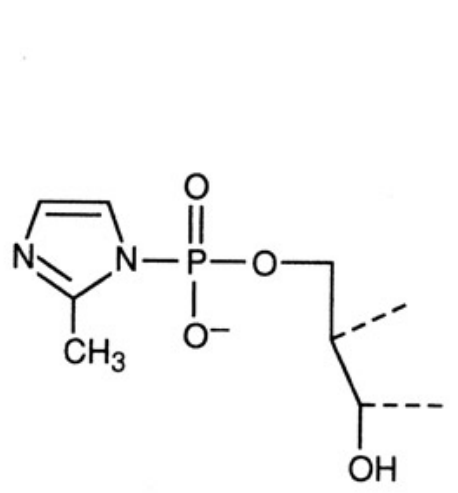

IX

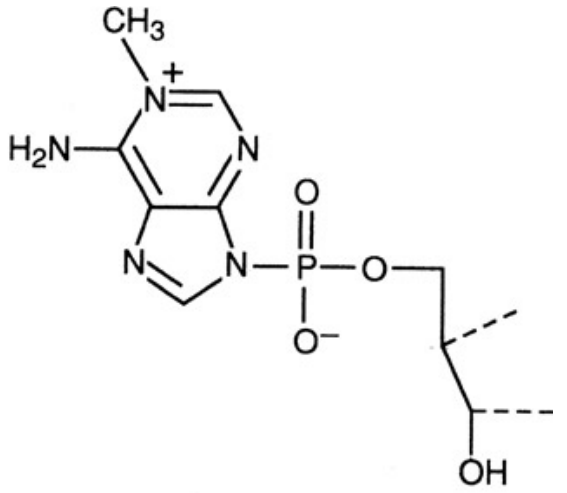

$X$ (b)

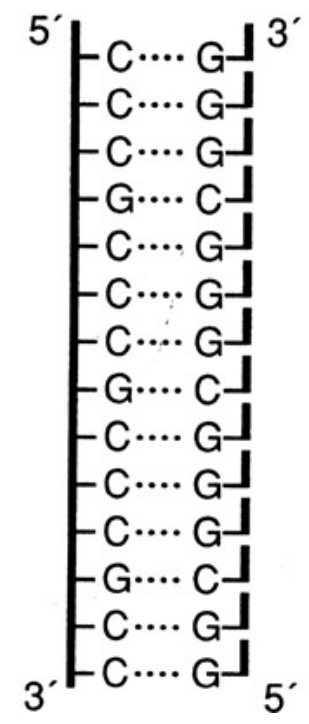

(c)

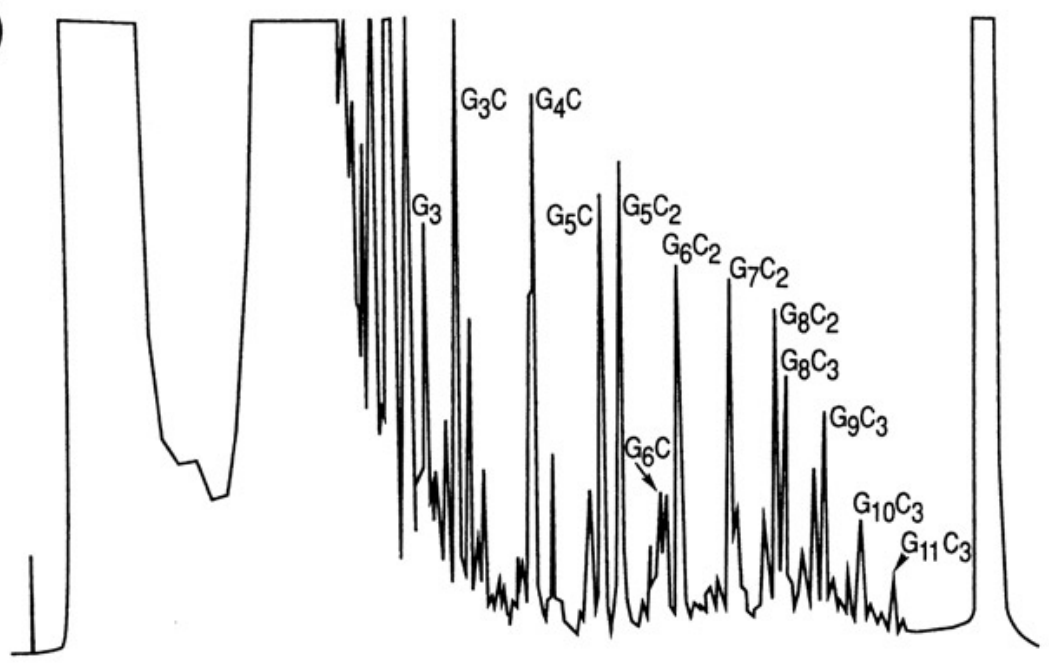

FIG. 7. (a) The structures of some activated nucleotides used in the prebiotic synthesis of oligonucleotides. (b) Oversimplified diagram showing activated mononucleotides aligned on a d(CCCGCCCGCCCGCC) template. (c) Electrophoresis of the products formed from activated monomers aligned on the d(CCCGCCCGCCCGCC) template shown in (b) above. The composition of the oligomers corresponding to major products is indicated. Degradation with specific RNAases showed that each major product is complementary to a subsequence of the template.

and inorganic phosphate, as described above. Then the nucleoside polyphosphates could have polymerized slowly or they could have been converted to phosphoramidates that polymerized more rapidly.

Nucleoside $5^{\prime}$-phosphorimidazolides oligomerize in aqueous solution, but in the absence of a catalyst yield only a complex mixture of short linear and cyclic products. A number of metal ions are effective catalysts for this class of polymerization (Sawai \& Orgel, 1975; Sawai, 1976), in particular $\mathrm{Pb}^{++}$(Sawai, 1976; Sleeper \& Orgel, 1979). Long homo- and hetero-oligomers are obtained using this metal ion when the reaction is carried out in eutectic solution (Kanavarioti et al., 2001; Monnard et al.,
2003). The uranyl ion is another very efficient catalyst in aqueous solution, leading to the synthesis of oligomers up to at least 16 mers. These oligonucleotide products are predominantly $2^{\prime}-5^{\prime}$-linked (Sawai et al., 1989, 1992).

James Ferris and his coworkers have investigated in considerable detail a remarkable series of reactions in which an abundant clay mineral, montmorillonite, catalyzes the synthesis of long oligonucleotides from relatively dilute solutions of nucleoside phosphoramidates including the 5'phosphorimidazolides (Ferris et al., 2003). In some of their more recent experiments using a phosphoramidate based on 1-methyladenine (X; Figure 7a), they were able to identify oligomers up to 40 residues long (Huang \& 
Ferris, 2003) with about $80 \%$ of $3^{\prime}-5^{\prime}$ - phosphodiester linkages (Prabahar \& Ferris, 1997). This is one of the most impressive examples of the catalysis of a prebiotic reaction by a mineral that has been reported.

Montmorillonite is a clay with a layered aluminosilicate structure that readily expands to permit large molecules to enter the interlayers, and it is probable that new phosphodiester bonds are formed when the substrates are absorbed in the interlayers (Ertem \& Ferris, 1998). An extensive body of experimental work suggests that there are specific catalytic sites somewhere on or in the mineral that can be blocked by adsorbed but unreactive analogs of the substrates, for example dimethyladenine (Wang \& Ferris, 2001).

The regiospecificity of the polymerization is very dependent on the nature of the nucleoside base and the activating group. In some cases it can favor the formation of $3^{\prime}-5^{\prime}$ - over $2^{\prime}-5^{\prime}$-phosphodiester linkages by as much as a factor of four (Prabahar \& Ferris, 1997), but in other cases the regiospecificity is modest or favors the formation of $2^{\prime}-5^{\prime}$-phosphodiester bonds (Ertem \& Ferris, 1997). The enantiospecificty of the montmorillonite-catalyzed reaction is limited (Joshi et al., 2000). Clearly, this impressive example of mineral-based catalysis is efficient but not particularly specific with respect to the distribution of isomeric products. Nonetheless, products of the montmorillonite-catalyzed oligomerization of ImpC (VIII) can act as templates for the oligomerization of ImpG (VIII) (Ertem \& Ferris, 1997).

In summary, two procedures for the efficient oligomerization of nucleoside- $5^{\prime}$-phosphorimidazolides and related phosphoramidates have been reported, montmorillonite catalysis and metal ion catalysis by $\mathrm{Pb}^{++}$or uranyl ions. These are only indirect models of prebiotic synthesis, since the phosphoramidate substrates of the polymerizations are not likely to be prebiotic molecules.

\section{TEMPLATE-DIRECTED SYNTHESIS}

The replication of RNA without the help of protein enzymes is an essential feature of the RNA World hypothesis. It seems probable, but by no means certain, that the synthesis of complementary RNA on a preformed RNA template, without the help of any informational catalyst, played a part in the origin of the RNA World (Orgel, 2003). We will review experiments on nonenzymatic template-directed synthesis here. Later we will discuss briefly ribozymecatalyzed template-directed synthesis, which is likely to have evolved in the RNA World before the "invention" of protein synthesis.

The basic principle of template-directed synthesis is a simple one (Figure $7 \mathrm{~b}$ ). If a polynucleotide is incubated with an appropriate mixture of complementary mononucleotides or short oligonucleotides at a sufficiently low temperature, in many cases a double- or triple-helical complex is formed (Howard et al., 1966). These complexes are structurally similar to double- or triple-stranded nucleic acids, but one chain is interrupted. Thus the template brings complementary activated monomers or short oligomers together and facilitates their ligation. Whenever a complementary complex is formed, the template influences the ligation reaction, but the devil is in the details. The ligation reaction may be more or less efficient and may lead to a greater or lesser excess of $3^{\prime}-5^{\prime}$-phosphodiester linkages over $2^{\prime}-5^{\prime}$-linkages. The objective of most research programs in this field has been to find conditions that lead to the efficient synthesis of predominantly $3^{\prime}-5^{\prime}-$ linked oligonucleotides for as broad a range of template sequences as possible.

The first experiments on template-directed synthesis of oligonucleotides were reported by Naylor and Gilham who showed that a $\mathrm{dA}_{12}$ template catalyzed the synthesis of $\mathrm{T}_{12}$ from two $\mathrm{T}_{6}$ molecules when a water-soluble carbodiimide was used as the condensing agent (Naylor \& Gilham, 1966). Zoe Shabarova and her coworkers have reported a large number of related experiments using different deoxy-templates, deoxy-substrates, and activating agents (Shabarova, 1988). We will not discuss this interesting and extensive literature because it is unlikely to be relevant to the origin of the RNA World. Experiments on RNA synthesis necessarily used activated ribonucleotide monomers or short oligomers as substrates, but often used DNA templates when RNA heteropolymers were not easily available. Water-soluble carbodiimides were initially used as activating agents (Sulston et al., 1968a, 1968b, 1969). In these experiments complex mixtures of isomeric short oligonucleotide products were obtained.

More recent work in the area of template-directed synthesis from mononucleotides has employed preactivated substrates, phosphorimidazolides, or closely related phosphoramidates (Figure 7a). The extensive and detailed literature on this topic has been reviewed (Joyce, 1987; Orgel, 1992; Kozlov \& Orgel, 2000), so only the main conclusions will be presented here. The cited reviews should be consulted for experimental procedures and quantitative results. Nucleoside-5'-triphosphates, which might seem an obvious choice of substrates in experiments with nucleotide monomers, cannot easily be used in laboratory experiments because they react too slowly at temperatures below the melting points of the helical complexes that they form. Studies of the spontaneous template-directed ligation of oligonucleotides terminated by a $5^{\prime}$-triphosphate group, however, have led to interesting conclusions, as we will see.

The first efficient and regiospecific polymerization reactions to be reported were the syntheses of long oligoguanylic acids (oligoGs) on poly $(\mathrm{C})$ templates using guanosine-5'-phosphorimidazolide (VIII; ImpG) as the 
activated monomer. The reaction showed a remarkably specific dependence on divalent metal ions. In the presence of $\mathrm{Mg}^{++}$and $\mathrm{Pb}^{++}$, the products were almost exclusively $2^{\prime}-5^{\prime}$-linked (Lohrmann \& Orgel, 1980), while in the presence of $\mathrm{Mg}^{++}$and $\mathrm{Zn}^{++}$ions virtually pure $3^{\prime}-5^{\prime}-$ linked oligomers were formed (Bridson \& Orgel, 1980). If neither $\mathrm{Pb}^{++}$nor $\mathrm{Zn}^{++}$was present, no long oligomers were obtained. This reaction was restricted to the synthesis of oligo $(\mathrm{G}) \mathrm{s}$ on a poly $(\mathrm{C})$ template and could not be extended to incorporate bases other than $\mathrm{G}$ on homo- or hetero-oligonucleotide templates.

It was found, surprisingly, that when 2-methyl imidazole replaced imidazole in the activated nucleotide (IX; to give 2-MeImpG) the synthesis of long oligo(G)s on a poly $(\mathrm{C})$ template no longer required the presence of any metal ion other than $\mathrm{Mg}^{++}$. In this context, 2-Meimidazole seems unique since neither imidazole nor its 2-ethyl derivative can substitute for it. Furthermore, the product oligomers formed from 2-MeImpG are almost exclusively $3^{\prime}-5^{\prime}$-linked (Inoue \& Orgel, 1981). One further advantage of using the 2-methyl imidazolides is that it allows the copying of heteropolymers containing all four bases, but only if the template contains at least $60 \%$ of $\mathrm{C}$ residues (Joyce, 1987). This latter restriction rules out the possibility of repeated rounds of replication, since the product of a successful template-directed oligomerization contains at most $40 \%$ of $\mathrm{C}$ residues and cannot, therefore, act efficiently as a template.

There is now substantial evidence that the templatedirected oligomerization of 2-Me-imidazole derivatives proceeds best in double helices that adopt the A-form nucleic acid structure (Kurz et al., 1997, 1998; Kozlov et al., 1999b, 2000b). RNA sequences are superior to DNA sequences as templates, but the general features of the reactions are similar for RNA and DNA templates (Zielinski et al., 2000). Nucleic acid analogs that tend to preorganize in the A-form DNA structure are usually excellent templates (Kozlov et al., 1999b, 2000b).

The sequence dependence of the reactions has been studied extensively using hairpin oligodeoxynucleotides as substrates (Wu \& Orgel, 1992a, 1992b, 1992c; Hill et al., 1993). Incorporation of $G$ opposite $C$ in the template is most efficient, while incorporation of $\mathrm{U}$ opposite $A$ is least efficient. Incorporation of A opposite $U$ or of $C$ opposite $\mathrm{G}$ is of intermediate efficiency. A pair of adjacent A residues in the template is an almost complete barrier to further synthesis. The fidelity of these reactions is usually very good, but with one notable exception: wobble pairing of $\mathrm{G}$ opposite $\mathrm{U}$ leads to extensive misincorporation of G, particularly on some RNA templates. The results of a long series of detailed studies show, therefore, that a wide variety of DNA or RNA sequences can be copied, but replication is not possible in this system (Joyce, 1987). The results of copying an especially favorable sequence,
deoxy(CCGCCCGCCCGCCC), are shown in Figure 7c (Acevedo \& Orgel, 1987).

Any prebiotic synthesis that yields ribonucleotides would produce racemates. Unfortunately, the L-enantiomers of activated nucleotides are efficient inhibitors of template-directed synthesis using the naturally occuring D-enantiomers (Joyce et al., 1984). This difficulty, often described as enantiomeric cross-inhibition, is not easily overcome without making substantial changes to the nature of the backbone of the template (Kozlov et al., 1999a). This is a major obstacle to any scheme for polynucleotide replication from plausibly prebiotic, monomeric substrates.

The ligation of short oligonucleotides activated as phosphorimidazolides has been studied less extensively. When very short oligomers activated as phosphorimidazolides are used as substrates, the efficiency and regiospecificity of the reaction depends very strongly and unpredictably on the sequences of the substrates (Ninio \& Orgel, 1978). However, with somewhat longer $3^{\prime},-5^{\prime}$-linked sequences ligation is efficient and yields predominantly $3^{\prime}-5^{\prime}$-linked products (Rohatgi et al., 1996b). The higher melting points of helices formed by oligomers, coupled with the possibility of using phosphorus-labeled substrates of high specific activity, has made possible a detailed study of the ligation of substrates activated as $5^{\prime}$-triphosphates (Rohatgi et al., 1996a, 1996b). Encouragingly, the ligation of 5'triphosphates, a close analog of enzymatic ligation, yields almost exclusively $3^{\prime}-5^{\prime}$-linked products. In the context of prebiotic chemistry, $3^{\prime}-5^{\prime}$-linked oligonucleotides are superior to mononucleotides as substrates with respect to regiospecificity, and they permit ligation over wider temperature ranges. However, it is not obvious that homochiral, exclusively $3^{\prime}-5^{\prime}$-linked oligomers are plausible prebiotic molecules (see previous section), and the fidelity of template-directed ligation of oligomers is lower than the fidelity of oligomerization of monomers.

\section{RIBOZYMES}

If one believes that the RNA World was the first organized biological world, one must postulate that a library of RNA strands with different sequences formed spontaneously on the primitive Earth and that this family of sequences included catalysts able to support self-replication of RNA. The idea of an RNA that performed some of the functions of an RNA polymerase is, therefore, an essential feature of the de novo RNA World hypothesis. It is much harder to decide which other functions would have needed to evolve in the RNA World once replication got started. Presumably catalysts for some metabolic reactions were required for the RNA World to become self-sustaining, but it is hard to guess which metabolic reactions. Instead of discussing ribozymes in general, we will review very briefly what is 
known about the ribozyme-catalyzed reactions that seems most relevant to the origin of the RNA World. The whole range of ribozyme-catalyzed reactions and the experimental protocols used in directed RNA-evolution experiments fall outside the scope of this article. Excellent accounts of these topics are available in two general reviews (Wilson \& Szostak, 1999; Joyce, 2004).

Ribozymes that occur in living organisms, although important, are rather limited in the range of reactions that they catalyze. The initial discoveries of Cech and Altman identified ribozymes that cut and ligate naturally occurring RNA (Kruger et al., 1982; Guerrier-Takada et al., 1983). With one important exception, the ribozymes that have been discovered subsequently in nature perform the same kind of functions. There is no evidence that transcription or RNA replication involve ribozyme catalysis. The most important ribozyme in nature is the ribosome. It is now clear that the peptide-bond-forming step of protein synthesis is catalyzed by the RNA of the ribosome without direct involvement of the proteins (Steitz \& Moore, 2003). This is the smoking gun that has led to the more general acceptance of the RNA World hypothesis. Unfortunately, our rapidly improving understanding of protein synthesis is unlikely to throw much light on the origin of the RNA World, since the invention of protein synthesis marked the beginning of its decline.

In vitro methods have been used to isolate RNA molecules that bind with high specificity to selected small organic molecules or to peptides and proteins (Puglisi \& Williamson, 1999). In principle, it should be possible to extend this type of procedure to obtain RNAs that bind to almost any water-soluble polymer or to any structured solid surface, including the surfaces of specific minerals or rocks. Selection of RNAs that perform catalytic functions required the invention of more complicated experimental protocols but is now a routine laboratory procedure (Wilson \& Szostak, 1999; Joyce, 2004). It is clear that a great variety of reactions can be catalyzed by RNA. On the one hand, an RNA that catalyzes the racemization of a sterically hindered biphenyl is a typical and interesting example of a ribozyme that brings about a reaction that has no obvious relation to biochemistry (Prudent et al., 1994). On the other, the RNA-catalyzed synthesis of 4-thiouridine$5^{\prime}$-phosphate from 4-thiouracil and 5-phosphoribosyl-1pyrophosphate is typical of the type of riboenzymatic reaction that, according to the RNA-first scenario, might have evolved when the availability of prebiotic nucleotides declined (Unrau \& Bartel, 1998). However, at the very beginning of the evolution of the RNA World only one function was essential, namely catalysis of RNA replication. Remarkable progress has been made in this area.

Bartel and his coworkers have been able to evolve a catalytic RNA that has many of the essential properties of an RNA polymerase (Johnston et al., 2001). This rather

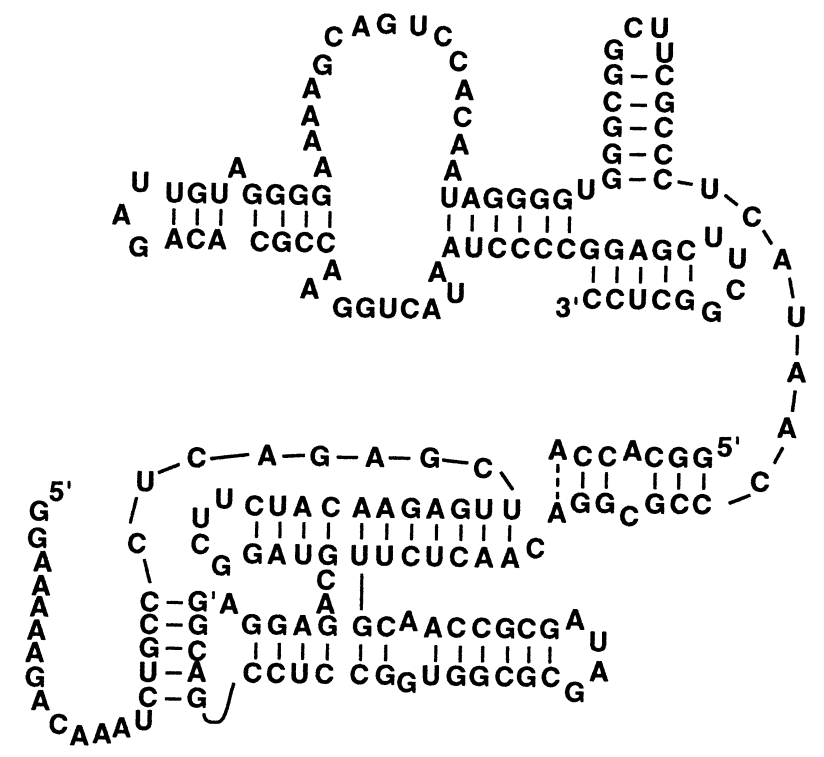

FIG. 8. A ribozyme that functions as an RNA-dependent RNA polymerase. Redrawn with modification from Robertson et al. (2001).

complicated molecule (Figure 8), when presented with an arbitrary, single-stranded RNA template, an RNA primer, and a mixture of the four nucleoside triphosphates, will synthesize the complement of the template. At present, templates that contain more than 14 residues cannot be copied effectively, but it seems likely that further in vitro evolution will lead to the isolation of a ribozyme capable of copying much longer RNAs. The isolation of such a ribozyme would constitute a major advance in attempts to understand the origin of life. However, the formidable problem of separating the double-stranded product of the copying reaction so as to permit a second round of copying would remain to be solved.

\section{THE MOLECULAR BIOLOGISTS' DREAM}

The RNA-first scenario for the origin of the RNA World that we have described as the 'Molecular Biologists' Dream (Joyce \& Orgel, 1999) can be strung together from optimistic extrapolations of the various achievements of prebiotic chemistry and directed RNA evolution described above. First we suppose that nucleoside bases and sugars were formed by prebiotic reactions on the primitive Earth and/or brought to the Earth in meteorites, comets, etc. Next, nucleotides were formed from prebiotic bases, sugars, and inorganic phosphates or polyphosphates, and they accumulated in an adequately pure state in some special little "pool." A mineral catalyst at the bottom of the pool-for example, montmorillonite - then catalyzed the formation of long single-stranded polynucleotides, some of which were then converted to complementary 
double strands by template-directed synthesis. In this way a library of double-stranded RNAs accumulated on the primitive Earth.

We suppose that among the double-stranded RNAs there was at least one that on melting yielded a (singlestranded) ribozyme capable of copying itself and its complement. Copying the complement would then have produced a second ribozyme molecule, and then repeated copying of the ribozyme and its complement would have lead to an exponentially growing population. In this scenario this is where natural selection takes over. Darwin suggested that all life is descended from one or a few simple organisms that evolved on the Earth long ago. According to the more radical scenario of the Molecular Biologists' Dream, the whole biosphere descends from one or a few replicating polynucleotides that formed on the primitive Earth about four billion years ago. Of course, there are still a few problems in prebiotic chemistry that must be solved before the Dream can be turned into a convincing theory! In addition, a plausible prebiotic mechanism for keeping together ribozymes and the products of their activity, for example, enclosure within a membrane, must be demonstrated (see below).

\section{RNA LATER}

Although tentative solutions to most of the problems that arise in attempting to achieve a prebiotic synthesis of RNA have been offered, nearly every one of them, as we have seen, is problematic. The synthesis of ribose leads to a complex mixture of sugars, with ribose as only a minor constituent under most conditions. The synthesis of purines nucleosides directly from ribose and a base is inefficient, while the only available prebiotic synthesis of the pyrimidine nucleosides starts from arabinose-3phosphate, a marginally prebiotic molecule. Phosphorylation of nucleosides leads to a complex mixture of isomeric mono- and polyphosphates, while polymerization even of pure nucleoside- $5^{\prime}$-phosphates leads to a product with mixed phosphodiester linkages. The phosphorimidazolides used in most studies of both template-directed and of template-independent synthesis are unlikely to be prebiotic molecules. It is possible that all of these, and many other difficulties will one day be overcome and that a convincing prebiotic synthesis of RNA will become available. However, many researchers in the field, myself included, think that this is unlikely and that there must be a different kind of solution to the problem of the origin of the RNA World.

Graham Cairns-Smith was the first person to emphasize the complexity of RNA and how improbable it is that RNA could have formed de novo on the primitive Earth. He suggested that the first system on the primitive Earth that was capable of evolving by natural selection was a self-reproducing clay (Cairns-Smith, 1982), but he also mentioned the possibility of a genetic system based on a linear polymer simpler than RNA (Cairns-Smith \& Davies, 1977). He thought that the original mineral (or simple organic) genetic system "invented" RNA and was subsequently displaced by it, and he introduced the term "genetic takeover" to describe the displacement of one genetic material by another. There is as yet no experimental support for the idea of a self-replicating, informational clay mineral. The possibility of genetic takeover from a simpler self-replicating organic polymer has become a central issue in discussions of the origin of the RNA World.

The idea that some simpler genetic system preceded RNA opens Pandora's box. There is very little to constrain the type of molecule involved or the environment in which it first functioned. Perhaps RNA is the "invention" of a completely different earlier world that operated under "extreme" conditions of temperature, $\mathrm{pH}$, and/or pressure. Perhaps the original genetic system was inorganic or included an essential inorganic component. Perhaps replication could initially take place only on the surface of some particular mineral or only at a particular kind of complex defect site on a particular mineral. Perhapsexperimental work has not begun to explore these possibilities. Instead, a few polymers fairly closely related to RNA have been examined as possible self-pairing systems that could have acted as precursors of RNA. Here, we can only review briefly some of the more important results insofar as they are related to prebiotic chemistry. Many nucleic-acid analogs have been investigated as potential antisense inhibitors of protein synthesis. Since they form stable heteroduplexes with RNA it seems likely that two complementary strands of almost any one of them would form a more or less stable double helix, but this has rarely been studied experimentally.

The most extensive body of experimental work is that reported by Eschenmoser and his coworkers (Eschenmoser, 1999). They set out to explore systematically the properties of polymers in which the $3^{\prime}-5^{\prime}$-linked ribose-phosphate backbone of RNA (Figure 9a) was replaced by some other sugar-phosphate backbone. Here, we can only review briefly some of their more striking results. In early experiments they discovered that polymers with backbones based on 2'-3'-dideoxy-D-glucose (homo-DNA; Figure 9b) form stable double helices held together by standard WatsonCrick base pairing (Groebke et al., 1998). These double helices have a very different structure from those of double-stranded RNA, since they turn about the helix axis much more slowly. Consequently, it is not possible to form chimeric double helices between a strand of homo-DNA and a strand of RNA. The discovery of a structurally regular isomer of RNA, pyranosyl RNA, or pRNA (Figure 9c) was very surprising. If the furanose isomers of the nucleotides are replaced by their pyranose equivalents, it is 


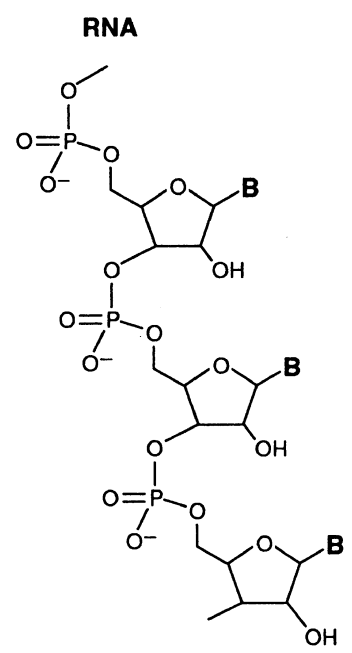

(a)

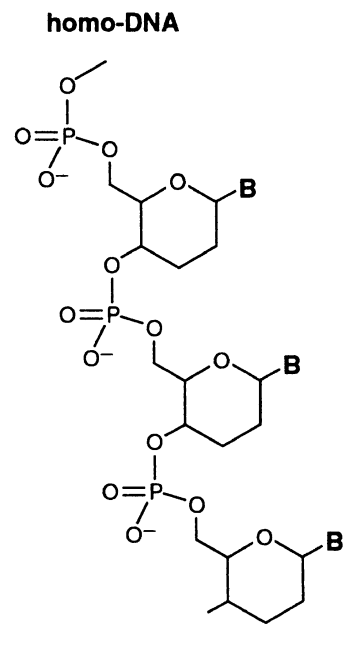

(b)

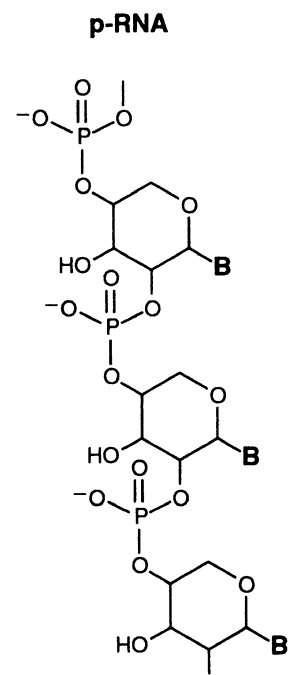

(c)

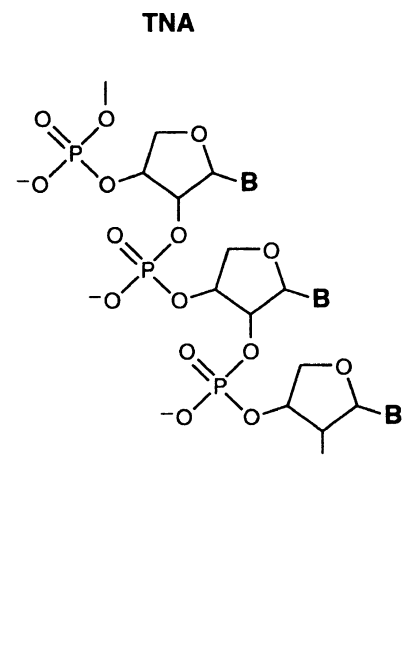

(d)

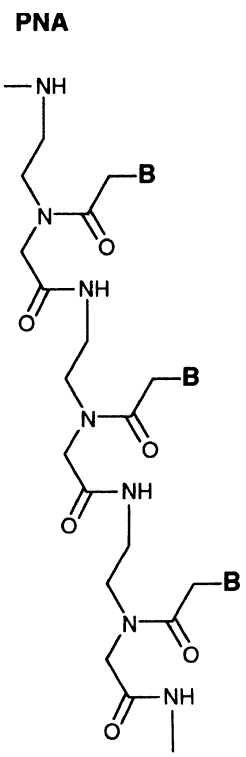

(e)

FIG. 9. The structures of single strands of (a) RNA, (b) homo-DNA, (c) p-RNA, (d) TNA, and (e) PNA.

still possible to form a double-stranded, base-paired double helix (Pitsch et al., 2003). Again, the structure of the helix is incompatible with that of RNA.

The analogs discussed above are different from but not simpler than RNA. More recently it has been shown that threose-based nucleotides are also capable of forming base-paired double helices (Schoning et al., 2000). Threose nucleic acids (TNAs), unlike the nucleic acid analogs discussed above, form stable heteroduplexes with RNA. This is surprising, because the number of atoms in the backbone-repeat of TNA is five (Figure 9d) rather than the six (or seven) that occur in RNA and in all previously studied base-pairing RNA analogs. It turns out that by maximally extending the threose-phosphate moiety it can be stretched out to roughly match the repeat length in RNA. TNA is the first base-pairing analog of RNA that is simpler than RNA in the sense that it is based on monomers, which can be synthesized more easily than the standard nucleotides. While it is not suggested that TNA was a precursor of RNA on the primitive Earth, the results obtained with TNA are encouraging because they suggest that even simpler self-replicating nucleic acid analogs may exist and that some of them may be able to adopt structures very similar to that of RNA.

Peptide nucleic acids (PNAs) are another extensively studied group of antisense nucleic acid analogs (Figure 9e) that have been discussed in the context of prebiotic chemistry (Egholm et al., 1992). The monomers contain the usual nucleic acid bases but are achiral and free of phosphate. Pairs of complementary PNA oligomers form
Watson-Crick base-paired double helices in aqueous solution. PNAs, besides forming these double helices, also form very stable chimeric double helices with nucleic acids (Egholm et al., 1993). Solutions of double-helical homoduplexes formed by underivatized PNA must contain equal proportions of left- and right-handed helices since PNA is achiral. However, the covalent attachment of chiral molecules, for example, amino acids or nucleotides, to the termini of one of the strands of a PNA double helix has been shown to bias the ratio of the concentrations of the two mirror-image helices.

PNA has been investigated as a model of a potential genetic material that is free of phosphate. PNA templates catalyze the oligomerization of activated nucleotides and the ligation of complementary oligonucleotides (Schmidt et al., 1997). It is also possible to form RNA/PNA chimeras on either RNA or PNA templates (Koppitz et al., 1998) and to show how chiral information can be transmitted through an intrinsically achiral PNA double-helix (Kozlov et al., 2000a). These experiments suggest one way in which genetic takeover might occur. It has been claimed that PNAs are plausible prebiotic molecules and that PNA may have been a precursor of RNA (Miller, 1997), but this seems doubtful because no straightforward prebiotic synthesis of the PNA monomers has been reported, and the activation of the carboxyl group of a PNA monomer would be expected to lead to rapid cyclization.

Diederichsen and his coworkers have described a novel pairing structure based on an alternating sequence of Dand L-amino acids (Figure 10). Sequences based on 
(a)
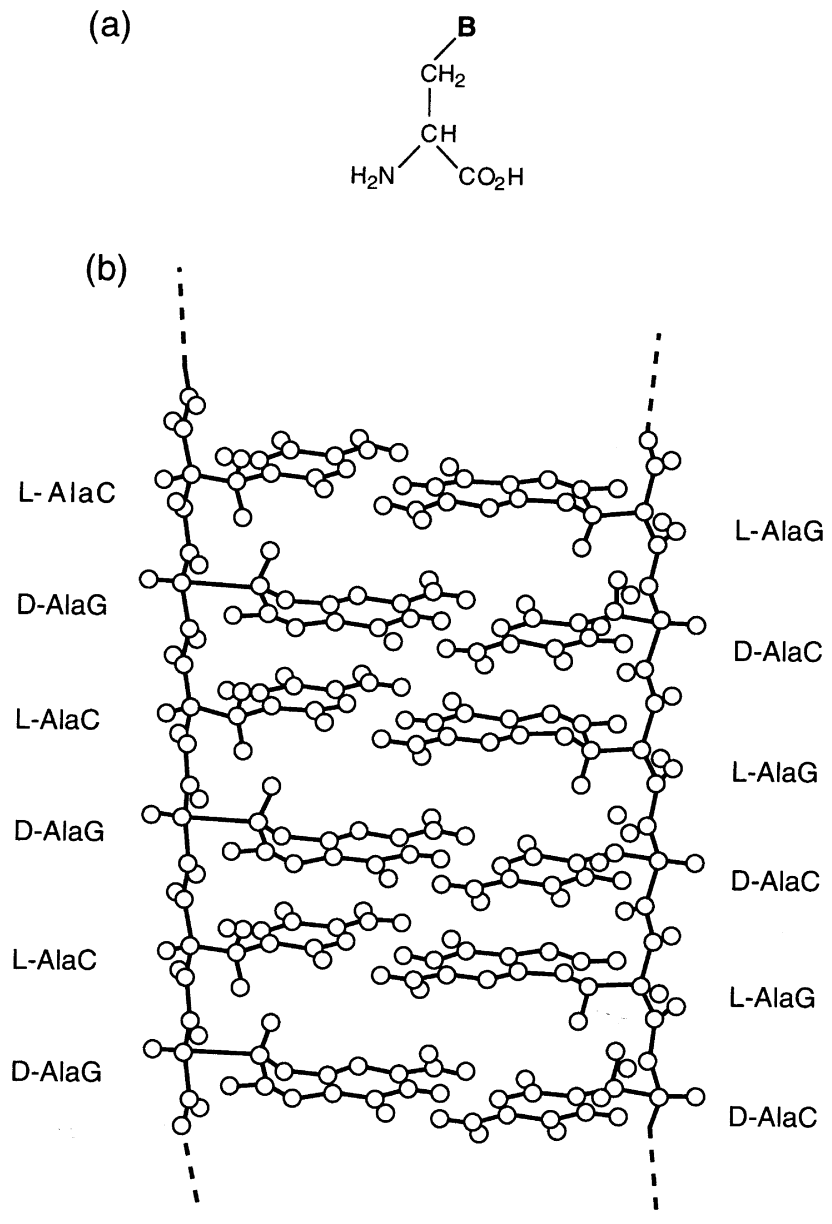

FIG. 10. (a) The amino acids that are combined to form ANA. $\mathrm{B}$ designates a standard nucleotide base. (b) The proposed basepaired structure formed by alternating ANA peptides. (Redrawn with slight modifications from, Diederichsen, U. (1997). Alanyl PNA: evidence for linear band structures based on guaninecytosine base pairs, Angew Chem Intl Ed Engl 36(17):1886.)

$\alpha$-amino acids of a single chirality cannot form pairing structures because of geometric constraints, but peptides in which the two enantiomers alternate are ideally suited for interchain interactions. Taking advantage of this observation, Diederichsen and his coworkers have made a detailed study of ANAs, alternating peptides based on relatively simple $\alpha$-amino acids that incorporate one of the standard nucleic-acid bases (Figure 10a). They find that complementary sequences form very stable antiparallel double helices (Figure 10b; Diederichsen, 1996).

Diederichsen does not seem to have discussed ANAs in the context of prebiotic chemistry. However, pairing structures that form only if both enantiomers of their monomers are available are very attractive in this context. It is difficult to see how a single enantiomer of any chiral organic compound could have formed on the primitive Earth, except perhaps in some chiral microenvironment. The copying of an alternating polymer is, in principle, no more difficult than the copying of a homochiral polymer if the substrates are racemic. Both are subject to inhibition through the insertion of the "incorrect" enantiomer in much the same way. If a substantial proportion of the substrate monomers are incorporated into product, the use of an alternating template with a racemic substrate is advantageous. The incorporation of one enantiomer of the substrate into product on a homochiral template biases the composition of the system against further synthesis, but no such difficulty arises in the case of an alternating template.

All of the experimental studies described above envisage genetic materials that incorporate the standard nucleotide bases. The transition from an earlier genetic polymer to a later one is usually assumed to have taken place with conservation of sequence information, presumably via chimeric intermediates. There is a completely different possibility, namely that an earlier genetic system with a structure completely unrelated to RNA "invented" RNA. In this scenario it must be assumed that nucleotides or closely related molecules were synthesized and polymerized by the earlier system for some nongenetic function, and that these molecules somehow developed into molecular Frankensteins. There are obvious problems with this approach, but it does have one very attractive feature, namely that it suggests that the first genetic material may have been based on very simple monomers.

One of the outstanding challenges in the field is, therefore, to design pairing structures based on monomers that are much more easily synthesized than the standard nucleotides. The stability of the nucleic acid double helix depends on nonspecific stacking interactions between bases as well as on specific hydrogen-bonding interactions. It is not difficult to imagine simple informational polymers that might interact together in a sequence-specific manner. The specificity of interaction might depend on chargefor example, with aspartic acid pairing with arginine-or on size-for example, with asparagine pairing with glutamine. Hydrophobic interaction, covalent bonding, or coordination to shared metal ions are also attractive mechanisms for associating two chains in a sequence-specific manner. However, it is not easy to suggest simple, prebiotically plausible monomers that provide for stacking as well as for these potential interchain interactions. The possibility that simple, stable pairing structures can exist without the need for stacking, perhaps on the surface of a mineral, needs to be explored.

In summary, a number of polymers that form doublehelical structures through Watson-Crick base-pairing have been reported, but none of them is very much simpler in structure than RNA. The idea that RNA was "invented" by a simpler genetic system is now a popular one, but no convincing precursor system has been described. 


\section{ENCAPSULATION}

\section{Theoretical Considerations}

The last common ancestor of all living things was no doubt some kind of single-celled organism, a packet of proteins and nucleic acids, cofactors and so on, enclosed in a relatively impermeable lipid membrane. Were the "organisms" of the RNA World enclosed in a similar membrane from the very beginning, or was the cell membrane a late "invention" of the RNA World or an early "invention" of the RNA/protein world?

Molecules that stay together evolve together. This sums up the arguments in favor of compartmentalization. There are two important and distinct aspects of this generalization, one concerning small-molecule metabolites, etc., and the other concerning macromolecules. Evolution is at a severe disadvantage in enhancing the performance of an organism's metabolic enzymes unless the small molecules that they synthesize are retained long enough to be utilized by the producing macromolecules (or their near relatives). There is no place in evolution for charity, and to synthesize a useful molecule and hand it over to an unrelated competitor would constitute molecular charity. However, it must be recognized that molecular isolationism is likely to be a double-edged weapon as far as small molecules are concerned, for it inhibits the acceptance of any useful small molecules that are freely available in the environment. When we consider genetic and functional macromolecules with defined sequences, whether ribozymes or protein enzymes, rather than small-molecule metabolites, the situation is simpler. Since these macromolecules can never be supplied as free goods from outside, it almost always pays to keep them together, whether or not they have free access to the external environment.

The arguments presented so far suggest that it is always advantageous to keep together macromolecules that are involved in each others' synthesis, whether they are genetic or metabolic, but that compartmentalization within an impermeable membrane will only be useful when an organism has reached the stage of synthesizing for itself some or most of its metabolites. Intuitively, one might expect, therefore, that compartmentalization within a somewhat permeable membrane would be useful at first and that a more impermeable membrane would develop gradually as "enzymatic" synthesis took over from the use of prebiotically available small organic molecules. This seems to be a very reasonable scenario, but it clearly isn't the only scenario and it does assume the availability of suitable prebiotic lipids. If, at a very early stage in biochemical evolution, it was only necessary to keep macromolecules together and it was not necessary to contain small organic molecules, there are alternatives to encapsulation.

As we have seen, the easiest modification of an impermeable lipid membrane that would meet the requirements of colocalization for early prebiotic replication would be a membrane with holes or pores large enough to pass small molecules such as nucleotides but too small to pass RNA polymers. The existence of such vesicles in a prebiotic environment may be possible (see below). A less-organized structure, a coacervate or organic colloid to which RNA molecules could attach with high affinity, might form more easily. In the latter case a strong interaction would be needed to keep the RNA and the organic colloid together. Rocks and minerals, which must have been ubiquitous on the primitive Earth, provide another site for colocalization. There are strong theoretical arguments (Orgel, 1998) and some experimental evidence (Hill et al., 1998) showing that sufficiently long negatively charged oligomers adsorb almost irreversibly on anion-exchanging minerals. Since template-directed synthesis occurs without interference on many mineral surfaces (Schwartz \& Orgel, 1984), mineral particles might support replication until they became saturated with the descendents of a single ancestral RNA molecule. Further expansion would depend on the occasional colonization of a vacant mineral particle.

I do not believe that there is at present enough evidence to justify a choice among these possibilities. A scenario that I personally find attractive is one in which the very first replicators were "naked genes" adsorbed on the surface of mineral particles, and in which impermeable membrane caps were "invented" by the genetic system as it became metabolically competent. Escape from the mineral surface, enabled by the development of a closed spherical membrane would occur at a relatively late stage in evolution. However, most published experimental studies concerned with encapsulation assume that encapsulation in a more or less impermeable membrane was important from the beginning.

\section{Experimental Studies}

David Deamer and his coworkers (Deamer et al., 2002) have explored the possibility of forming membrane structures from prebiotic amphiphilic organic matter. In an early paper they described experiments in which they extracted samples of the Murchison meteorite with organic solvents, separated the mixture of extracted organic components by paper chromatography, and then examined the structures formed when the separated components were mixed with water. Many different structures were observed, most interestingly the membranous vesicles obtained with some but not all of the separated components. In a few cases, vesicles were observed that seemed to consist of an interior compartment surrounded by a double membrane; fluorescent molecules could be trapped in the interior of the structure (Deamer \& Pashley, 1989). More recently, very similar results have been obtained with amphiphylic material obtained in simulations of organic synthesis in 
interstellar ices subjected to UV irradiation (Dworkin et al., 2001). These studies suggest that the prebiotic formation of vesicles may be possible.

Another substantial body of experimental evidence concerns chemistry that occurs within vesicles formed from simple, but not prebiotically synthesized, organic molecules. Not surprisingly, protein enzymes function more or less normally within large-enough bilayer vesicles, and the enzymatic synthesis of nucleic acids within vesicles has been described (Chakrabarti et al., 1994; Oberholzer et al., 1995). In a related study, it was reported that particles of the clay mineral montmorillonite catalyze the formation of closed vesicles from micelles composed of simple aliphatic carboxylic acids and that particles of the clay become encapsulated within the vesicles (Hanczyc et al., 2003). Since montmorillonite is an excellent catalyst for the oligomerization of a number of activated nucleotides this might point to a route to a nucleic-acid-synthesizing system enclosed within a vesicle. It remains to be shown that montmorillonite catalysis of polynucleotide synthesis can occur within the vesicles and lead to the formation of trapped products.

The generation of an autonomous self-replicating system of RNA within a lipid vesicle requires the vesicle, as well as its contents, to be capable of exponential growth. In one series of experiments it was shown that vesicles composed of caprylic acid were effective catalysts for the hydrolysis of ethyl caprylate. The newly formed caprylic acid never appeared in solution but was incorporated directly into the vesicle walls, causing the vesicles to grow and ultimately to divide (Bachmann et al., 1992). Similar behavior was observed with suspensions of the insoluble anhydrides of oleic and caprylic acids (Walde et al., 1994).

In summary, it seems almost certain that RNA organisms as complicated as those that "invented" protein synthesis must have been enclosed in relatively impermeable membranes. However, it is not clear whether the very first self-replicating RNA molecules were enclosed in vesicles, attached to organic colloids, or adsorbed on mineral surfaces. Perhaps they were adsorbed to mineral particles within lipid membranes (Hanczyc et al., 2003).

\section{SUMMARY}

This review has focussed on experimental work designed to explain how RNA, directly or indirectly, could have appeared on the primitive Earth. It has catalogued the achievements in each pertinent area of research and also emphasized the gaps in our understanding. A more global summary may be useful.

The most impressive advances in the past decade or so have come in the field of RNA selection. Enough is already known to suggest that each of the steps needed to evolve from a library of randomly sequenced double- stranded RNAs to a self-sustaining RNA organism can be demonstrated in laboratory experiments. An advanced RNA organism would presumably need to be enclosed in a membrane. Attempts to develop prebiotically plausible lipid membranes are just beginning, but the early results are promising. There are already hints that a membrane capable of enclosing functional RNA molecules and expanding along with them could be put together from molecules as simple as monocarboxylic acid.

Considerable progress has also been made in understanding how a library of random sequence doublestranded RNA molecules might have arisen from a pool of activated nucleotides. The catalysis of the formation of long RNA strands by the clay mineral montmorillonite is remarkable. It suggests that mineral catalysis may provide the solution to many problems. Nonenzymatic, templatedirected copying of single-stranded RNA to generate double strands has been explored in detail. While exponential replication cannot be achieved using presently available methods, a wide range of single-stranded RNAs can be converted to double strands.

The prebiotic synthesis of nucleotides in a sufficiently pure state to support RNA synthesis cannot be achieved using presently known chemistry. Each of the steps needed to assemble a nucleotide from very simple starting materials was demonstrated early in the development of prebiotic chemistry, but the reactions were inefficient, nonspecific, or both. Some progress has been made in developing more specific prebiotic syntheses, but formidable difficulties remain. This has led some researchers to explore a major new approach to the problem of molecular evolutionthe search for polymers that could function as alternative genetic systems.

It is now clear that there are numerous double-stranded structures with backbones very different from that of RNA but held together by Watson-Crick base pairing. Investigation of these structures is a novel and fruitful branch of organic chemistry (and Astrobiology) regardless of whether it turns out to be relevant to the origin of life on the Earth. It also seems possible that there are pairing structures much simpler than RNA in the sense that their monomeric components can be synthesized much more easily than nucleotides. The discovery of TNA is encouraging, but structures that are independent of Watson-Crick base pairing are as yet unknown.

\section{FUTURE DIRECTIONS}

Prebiotic chemistry remains so diverse a field that it is by no means clear where the next important advances will occur. It seems likely that adsorption on and catalysis by minerals was essential for the origin of the RNA World, so increasing efforts to study heterogeneous reactions are to be anticipated. Since minerals are so varied in composition 
and structure, combinatorial methods will be required. It will be necessary to study each potentially important reaction in parallel on tens or hundreds of different mineral samples. Whether or not this approach will lead to the discovery of a plausible prebiotic route to the nucleotides, as the believers in the Molecular Biologists' Dream hope, remains to be seen, but it is likely that many novel mineral catalysts will be discovered in this way.

The search for pairing structures based on monomeric components that can be synthesized much more easily than nucleotides and, hopefully, that polymerize more readily has just begun. No doubt it will remain an active and expanding field. Whether or not it leads to a plausible scenario for a simple pre-RNA World, as advocates of "RNA late" hope, it is likely to generate some novel organic chemistry.

One must recognize that, despite considerable progress, the problem of the origin of the RNA World is far from being solved.

\section{ACKNOWLEDGEMENTS}

I thank Gerald Joyce for many useful comments on an earlier version of this review and Kathleen Murray for manuscript preparation.

\section{REFERENCES}

Acevedo, O.L. and Orgel, L.E. 1987. Non-enzymatic transcription of an oligodeoxynucleotide 14 residues long. J Mol Biol 197:187-193.

Anders, E. 1989. Pre-biotic organic matter from comets and asteroids. Nature 342:255-257.

Bachmann, P.A., Luisi, P.L., and Lang, J. 1992. Autocatalytic selfreplicating micelles as models for prebiotic structures. Nature 357:57-59.

Beck, A., Lohrmann, R., and Orgel, L.E. 1967. Phosphorylation with inorganic phosphates at moderate temperatures. Science 157:952.

Blochl, E., Keller, M., Wachtershauser, G., and Stetter, K.O. 1992. Reactions depending on iron sulfide and linking geochemistry with biochemistry. Proc Natl Acad Sci USA 89:8117-8120.

Botta, O. and Bada, J.L. 2002. Extraterrestrial organic compounds in meteorites. Surveys Geophys 23:411-467.

Breslow, R. 1959. On the mechanism of the formose reaction. Tetrahedron Lett 21:22-26.

Bridson, P.K. and Orgel, L.E. 1980. Catalysis of accurate poly(C)directed synthesis of $3^{\prime}-5^{\prime}$-linked oligoguanylates by $\mathrm{Zn}^{2+}$. J Mol Biol 144:567-577.

Butlerow, A. 1861. Formation synthetique d'une substance sucree. Compt Rend Acad Sci 53:145-147.

Cairns-Smith, A.G. 1982. Genetic Takeover and the Mineral Origin of Life. Cambridge: Cambridge University Press.

Cairns-Smith, A.G. and Davies, C.J. 1977. The design of novel replicating polymers. In Encyclopaedia of Ignorance. Duncan, R. and Weston-Smith, M., Eds., New York: Pergamon Press.
Chakrabarti, A.C., Breaker, R.R., Joyce, G.F., and Deamer, D.W. 1994. Production of RNA by a polymerase protein encapsulated within phospholipid vesicles. J Mol Evol 39:555-559.

Cheng, C., Fan, C., Wan, R., Tong, C., Miao, Z., Chen, J., and Zhao, Y. 2002. Phosphorylation of adenosine with trimetaphosphate under simulated prebiotic conditions. Orig Life Evol Biosph 32:219-224.

Chyba, C. and Sagan, C. 1992. Endogenous production, exogenous delivery and impact-shock synthesis of organic molecules: an inventory for the origins of life. Nature 355:125-132.

Cody, G.D., Boctor, N.Z., Filley, T.R., Hazen, R.M., Scott, J.H., Sharma, A., and Yoder, H.S., Jr. 2000. Primordial carbonylated ironsulfur compounds and the synthesis of pyruvate. Science 289:13371340.

Cooper, G., Kimmich, N., Belisle, W., Sarinana, J., Brabham, J., and Garrel, L. 2001. Carbonaceous meteorites as a source of sugar-related organic compounds for the early Earth. Nature 414:879-883.

Crick, F.H.C. 1968. The origin of the genetic code. J Mol Biol 38:367379.

Cronin, J.R. and Chang, S. 1993. Organic matter in meteorites: molecular and isotopic analysis of the Murchison meteorite. In The Chemistry of Life's Origin, pp. 209-258. Greenberg, J.M., MendozaGomez, C.X., and Pirronello, V., Eds., The Netherlands: Kluwer Academic Publishers,

Deamer, D., Dworkin, J.P., Sandford, S.A., Bernstein, M.P., and Allamandola, L.J. 2002. The first cell membranes. Astrobiology 2:371-381.

Deamer, D.W. and Pashley, R.M. 1989. Amphiphilic components of the Murchison carbonaceous chondrite: surface properties and membrane formation. Orig Life Evol Biosph 19:21-38.

Decker, P., Schweer, H., and Pohlmann, R. 1982. Identification of formose sugars, presumable prebiotic metabolites, using capillary gas chromatography/gas chromatography-mass spectrometry of $n$ butoxime trifluoroacetates on OV-225. J Chromatog 244:281-291.

Diederichsen, U. 1996. Pairing properties of alanyl peptide nucleic acids containing an amino acid backbone with alternating configuration. Angew Chem Int Ed Engl 35:445-448.

Dorr, M., Kassbohrer, J., Grunert, R., Kreisel, G., Brand, W.A., Werner, R.A., Geilmann, H., Appel, C., Robl, C., and Weigand, W. 2003. A possible prebiotic formation of ammonia from dinitrogen on iron sulfide surfaces. Angew Chem Int Ed Engl 42:1540-1543.

Dworkin, J., Deamer, D., Sandford, S., and Allamandola, L. 2001. Selfassembling amphiphilic molecules: synthesis in simulated interstellar/precometary ices. Proc Natl Acad Sci USA 98:815-819.

Egholm, M., Buchardt, O., Christensen, L., Behrens, C., Freier, S.M., Driver, D.A., Berg, R.H., Kim, S.K., Norden, B., and Nielsen, P.E. 1993. PNA hybridizes to complementary oligonucleotides obeying the Watson-Crick hydrogen-bonding rules. Nature 365:566-568.

Egholm, M., Buchardt, O., Nielsen, P.E., and Berg, R.H. 1992. Oligonucleotide analogues with an achiral peptide backbone. J Am Chem Soc 114:1895-1897.

Ertem, G. and Ferris, J.P. 1997. Template-directed synthesis using the heterogeneous templates produced by montmorillonite catalysis. A possible bridge between the prebiotic and RNA worlds. J Am Chem Soc 119:7197-7201.

Ertem, G. and Ferris, J.P. 1998. Formation of RNA oligomers on montmorillonite: site of catalysis. Orig Life Evol Biosph 28:485-499.

Eschenmoser, A. 1999. Chemical etiology of nucleic acid structure. Science 284: 2118-2124. 
Etaix, E. and Orgel, L.E. 1978. Phosphorylation of nucleosides in aqueous solution using trimetaphosphate: formation of nucleoside triphosphates. J Carbohydrates-Nucleosides-Nucleotides 5:91-110.

Ferris, J.P., Joshi, P.C., Wang, K.J., Miyakawa, S., and Huang, W. 2003. Catalysis in prebiotic chemistry: application to the synthesis of RNA oligomers. Adv Space Res in press.

Ferris, J.P. and Orgel, L.E. 1965. Aminomalononitrile and 4-amino5-cyanoimidazole in hydrogen cyanide polymerization and adenine synthesis. J Am Chem Soc 87:4976-4977.

Ferris, J.P. and Orgel, L.E. 1966a. Studies on prebiotic synthesis. I. Aminomalononitrile and 4-amino-5-cyanoimidazole. J Am Chem Soc 88:3829-3831.

Ferris, J.P. and Orgel, L.E. 1966b. An unusual photochemical rearrangement in the synthesis of adenine from hydrogen cyanide. J Amer Chem Soc 88:1074.

Ferris, J.P., Sanchez, R.A., and Orgel, L.E. 1968. Studies in prebiotic synthesis. 3. Synthesis of pyrimidines from cyanoacetylene and cyanate. J Mol Biol 33:693-704.

Ferris, J.P., Zamek, O.S., Altbuch, A.M., and Freiman, H. 1974. Chemical evolution. 18. Synthesis of pyrimidines from guanidine and cyanoacetaldehyde. J Mol Evol 3:301-309.

Fuller, W.D., Sanchez, R.A., and Orgel, L.E. 1972. Studies in prebiotic synthesis: VII. Solid-state synthesis of purine nucleosides. $\mathrm{J} \mathrm{Mol}$ Evol 1:249-257.

Gabel, N.W. and Ponnamperuma, C. 1967. Model for origin of monosaccharides. Nature 216:453-455.

Gesteland, R.F., Cech, T.R., and Atkins, J.F. 1999. The RNA World, 2nd ed. Cold Springs Harbor, NY: Cold Springs Harbor Press.

Gilbert, W. 1986. The RNA World. Nature 319:618.

Goo, J. 1961. Comets and the formation of biochemical compounds on the primitive Earth. Nature 190:389-390.

Groebke, K., Hunziker, J., Fraser, W., Peng, L., Diederichsen, U., Zimmermann, K., Holzner, A., Leumann, C., and Eschenmoser, A. 1998. Why pentose- and not hexose-nucleic acids? Part V. Purine-purine pairing in homo-DNA: Guanine, isoguanine, 2,6diaminopurine, and xanthine. Helv Chim Acta 81:375-474.

Guerrier-Takada, C., Gardiner, K., Marsh, T., Pace, N., and Altman, S. 1983. The RNA moiety of ribonuclease $\mathrm{P}$ is the catalytic subunit of the enzyme. Cell 35:849-857.

Halmann, M., Sanchez, R.A., and Orgel, L.E. 1969. Phosphorylation of D-ribose in aqueous solution. J Org Chem 34:3702-3703.

Hanczyc, M.M., Fujikawa, S.M., and Szostak, J.W. 2003. Experimental models of primitive cellular compartments: encapsulation, growth, and division. Science 302:618-622.

Handschuh, G.J., Lohrmann, R., and Orgel, L.E. 1973. The effect of $\mathrm{Mg}^{2+}$ and $\mathrm{Ca}^{2+}$ on urea-catalyzed phosphorylation reactions. $\mathrm{J} \mathrm{Mol}$ Evol 2:251-262.

Hill, A. and Orgel, L.E. 2002. Synthesis of adenine from HCN tetramer and ammonium formate. Orig Life Evol Biosph 32:99-102.

Hill, A.R., Jr., Bohler, C., and Orgel, L.E. 1998. Polymerization on the rocks: negatively-charged alpha-amino acids. Orig Life Evol Biosph 28:235-243.

Hill, A.R., Jr., Orgel, L.E., and Wu, T. 1993. The limits of template-directed synthesis with nucleoside-5'-phosphoro(2methyl)imidazolides. Orig Life Evol Biosph 23:285-290.

Howard, F.B., Frazier, J., Singer, M.F., and Miles, H.T. 1966. Helix formation between polyribonucleotides and purines, purine nucleosides and nucleotides. II. J Mol Biol 16:415-439.
Huang, W. and Ferris, J.P. 2003. Synthesis of 35-40 mers of RNA oligomers from unblocked monomers. A simple approach to the RNA world. Chem Commun (Camb) 12:1458-1459.

Huber, C. and Wachtershauser, G. 1997. Activated acetic acid by carbon fixation on $(\mathrm{Fe}, \mathrm{Ni}) \mathrm{S}$ under primordial conditions. Science 276:245247.

Huber, C. and Wachtershauser, G. 1998. Peptides by activation of amino acids with $\mathrm{CO}$ on $(\mathrm{Ni}, \mathrm{Fe}) \mathrm{S}$ surfaces: implications for the origin of life. Science 281:670-672.

Ingar, A.A., Luke, R.W., Hayter, B.R., and Sutherland, J.D. 2003. Synthesis of cytidine ribonucleotides by stepwise assembly of the heterocycle on a sugar phosphate. Chembiochem 4:504-507.

Inoue, T. and Orgel, L.E. 1981. Substituent control of the poly(C)directed oligomerization of guanosine 5-phosphoroimidazolide. J Amer Chem Soc 103:7666-7667.

Johnston, W.K., Unrau, P.J., Lawrence, M.S., Glasner, M.E., and Bartel, D.P. 2001. RNA-catalyzed RNA polymerization: accurate and general RNA-templated primer extension. Science 292:1319-1325.

Joshi, P.C., Pitsch, S., and Ferris, J.P. 2000. Homochiral selection in the montmorillonite-catalyzed and uncatalyzed prebiotic synthesis of RNA. Chem Com 24:2497-2498.

Joyce, G.F. 1987. Nonenzymatic template-directed synthesis of informational macromolecules. Cold Spring Harb Symp Quant Biol 52:41-51.

Joyce, G.F. 2004. Directed evolution of nucleic acid enzymes. Ann Rev of Biochem 73:791-836.

Joyce, G.F. and Orgel, L.E. 1999. Prospects for understanding the origin of the RNA world. In The RNA World, 2nd ed., pp. 49-77. Gesteland, R.F., Cech, T.R., and Atkins, J.F., Eds., Cold Spring Harbor: Cold Spring Harbor Press.

Joyce, G.F., Visser, G.M., van Boeckel, C.A., van Boom, J.H., Orgel, L.E., and van Westrenen, J. 1984. Chiral selection in poly(C)-directed synthesis of oligo(G). Nature 310:602-604.

Kanavarioti, A., Monnard, P.A., and Deamer, D.W. 2001. Eutectic phases in ice facilitate nonenzymatic nucleic acid synthesis. Astrobiology 1:271-281.

Kasting, J.F. and Brown, L.L. 1998. The early atmosphere as a source of biogenic compounds. In The Molecular Origins of Life, pp. 35-56. Brack, A., Ed., New York: Cambridge University Press.

Kieboom, A. and VanBekkum, H. 1984. Aspects of the chemical conversion of glucose. Rec Tr Chim Pays-Bas 103:1-12.

Koppitz, M., Nielsen, P.E., and Orgel, L.E. 1998. Formation of oligonucleotide-PNA-chimeras by template-directed ligation. $J$ Am Chem Soc 120:4563-4569.

Kozlov, I.A. and Orgel, L.E. 2000. Nonenzymatic template-directed synthesis of RNA from monomers (translated from Molekulamaya Biologlya). Molecular Biology 34:781-789.

Kozlov, I.A., Orgel, L.E., and Nielsen, P.E. 2000a. Remote enantio selection transmitted by an achiral PNA backbone. Angew Chem Int Ed 39:4292-4295.

Kozlov, I.A., Politis, P.K., Pitsch, S., Herdewijn, P., and Orgel, L.E. 1999a. A highly enantio-selective hexitol nucleic acid template for nonenzymatic oligoguanylate synthesis. J Am Chem Soc 121:11081109.

Kozlov, I.A., Politis, P.K., Van Aerschot, A., Busson, R., Herdewijn, P., and Orgel, L.E. 1999b. Nonenzymatic synthesis of RNA and DNA oligomers on hexitol nucleic acid templates: the importance of the A structure. J Am Chem Soc 121:2653-2656. 
Kozlov, I.A., Zielinski, M., Allart, B., Kerremans, L., Van Aerschot, A., Busson, R., Herdewijn, P., and Orgel, L.E. 2000b. Nonenzymatic template-directed reactions on altritol oligomers, preorganized analogues of oligonucleotides. Chemistry 6:151-155.

Krishnamurthy, R., Guntha, S., and Eschenmoser, A. 2000. Regioselective $\alpha$-phosphorylation of aldoses in aqueous solution. Angew Chem Int Ed Engl 39:2281-2285.

Kruger, K., Grabowski, P.J., Zaug, A.J., Sands, J., Gottschling, D.E., and Cech, T.R. 1982. Self-splicing RNA: autoexcision and autocyclization of the ribosomal RNA intervening sequence of Tetrahymena. Cell 31:147-157.

Kurz, M., Gobel, K., Hartel, C., and Gobel, M. 1997. Nonenzymatic oligomerization of ribonucleotides on guanosine-rich templates: suppression of the self-pairing of guanosine. Angew Chem Int Ed Engl 8:842-845.

Kurz, M., Gobel, K., Hartel, C., and Gobel, M. 1998. Acridine-labeled primers as tools for the study of nonenzymatic RNA oligomerization. Helv Chim Acta 81:1156-1180.

Lohrmann, R. 1977. Formation of nucleoside 5'-phosphoramidates under potentially prebiological conditions. J Mol Evol 10:137-154.

Lohrmann, R. and Orgel, L.E. 1968. Prebiotic synthesis: phosphorylation in aqueous solution. Science 161:64-66.

Lohrmann, R. and Orgel, L.E. 1971. Urea-inorganic phosphate mixtures as prebiotic phosphorylating agents. Science 171:490-494.

Lohrmann, R. and Orgel, L.E. 1980. Efficient catalysis of polycytidylic acid-directed oligoguanylate formation by $\mathrm{Pb}^{2+}$. J Mol Biol 142:555567.

Lundstrom, F.O. and Whittaker, C.W. 1937. Chemical reactions in fertilizer mixtures. Effect of ammoniation on urea component of superphosphate mixtures. Ind Eng Chem 29:61-68.

Miller, S.L. 1953. A production of amino acids under possible primitive earth conditions. Science 117:528-529.

Miller, S.L. 1957. The mechanism of synthesis of amino acids by electric discharges. Biochim Biophys Acta 23:480-489.

Miller, S.L. 1997. Peptide nucleic acids and prebiotic chemistry. Nat Struct Biol 4:167-169.

Miyakawa, S., Cleaves, H.J., and Miller, S.L. 2002a. The cold origin of life: A. Implications based on the hydrolytic stabilities of hydrogen cyanide and formamide. Orig Life Evol Biosph 32:195-208.

Miyakawa, S., Cleaves, H.J., and Miller, S.L. 2002b. The cold origin of life: B. Implications based on pyrimidines and purines produced from frozen ammonium cyanide solutions. Orig Life Evol Biosph 32:209-218.

Miyakawa, S., Murasawa, K., Kobayashi, K., and Sawaoka, A.B. 2000. Abiotic synthesis of guanine with high-temperature plasma. Orig Life Evol Biosph 30:557-566.

Mizuno, T. and Weiss, A.H. 1974. Synthesis and utilization of formose sugars. In: Advances in Carbohydrate Chemistry and Biochemistry, v. 29, pp. 173-227. Tipson, R.W., and Horton, D., Eds., New York London: Academic Press.

Monnard, P.A., Kanavarioti, A., and Deamer, D.W. 2003. Eutectic phase polymerization of activated ribonucleotide mixtures yields quasiequimolar incorporation of purine and pyrimidine nucleobases. J Am Chem Soc 125:13734-13740.

Moravek, J. 1967. Formation of oligonucleotides during heating of a mixture of uridine $2^{\prime}\left(3^{\prime}\right)$-phosphate and uridine. Tetrahedron Lett 18:1707-1710.

Mueller, D., Pitsch, S., Kittaka, A., Wagner, E., Wintner, C.E., and Eschenmoser, A. 1990. Chemistry of alpha aminonitriles. Al- domerization of glycolaldehyde phosphate to racemic hexose $2,4,6$ triphosphates and (in presence of formaldehyde) racemic pentose 2,4-diphosphates: rac-Allose 2, 4, 6-triphosphate and racemic ribose 2,4-diphosphate are the main reaction products. Helvetica Chimica Acta 73:1410-1468.

Naylor, R. and Gilham, P.T. 1966. Studies on some interactions and reactions of oligonucleotides in aqueous solution. Biochemistry 5:2722-2728.

Nelson, K.E., Robertson, M.P., Levy, M., and Miller, S.L. 2001. Concentration by evaporation and the prebiotic synthesis of cytosine. Orig Life Evol Biosph 31:221-229.

Ninio, J. and Orgel, L.E. 1978. Heteropolynucleotides as templates for nonenzymatic polymerizations. J Mol Evol 12:91-99.

Oberholzer, T., Albrizio, M., and Luisi, P.L. 1995. Polymerase chain reaction in liposomes. Chem Biol 2:677-682.

Orgel, L. and Sulston, J. 1971. Polynucleotide replication and the origin of life. In Prebiotic and Biochemical Evolution, pp. 89-94. Kimball, A., and Oro, J., Eds., Amsterdam: North-Holland Publishing Company.

Orgel, L.E. 1968. Evolution of the genetic apparatus. $J$ Mol Biol 38:381-393.

Orgel, L.E. 1992. Molecular replication. Nature 358:203-209.

Orgel, L.E. 1998. Polymerization on the rocks: theoretical introduction. Orig Life Evol Biosph 28:227-234.

Orgel, L.E. 2000. Self-organizing biochemical cycles. Proc Natl Acad Sci USA 97:12503-12507.

Orgel, L.E. 2002. Is cyanoacetylene prebiotic? Orig Life Evol Biosph 32:279-281.

Orgel, L.E. 2003. Some consequences of the RNA world hypothesis. Orig Life Evol Biosph 33:211-218.

Orgel, L.E. 2004. Prebiotic adenine revisited: eutectics and photochemistry. Orig Life Evol Biosph in press.

Oro, J. 1961a. Mechanism of synthesis of adenine from hydrogen cyanide under possible primitive earth conditions. Nature 191:11931194.

Oro, J. 1961b. Comets and the formation of biochemical compounds on the primitive Earth. Nature 190:389-390.

Oro, J. and Kimball, A. 1960. Synthesis of adenine from ammonium cyanide. Biochem Biophys Res Commun 2:407-412.

Oro, J. and Kimball, A.P. 1961. Synthesis of purines under possible primitive earth conditions. I. Adenine from hydrogen cyanide. Arch Biochem Biophys 94:217-227.

Oro, J. and Kimball, A.P. 1962. Synthesis of purines under possible primitive earth conditions. II. Purine intermediates from hydrogen cyanide. Arch Biochem Biophys 96:293-313.

Osterberg, R. and Orgel, L.E. 1972. Polyphosphate and trimetaphosphate formation under potentially prebiotic conditions. J Mol Evol 1:241-248.

Osterberg, R., Orgel, L.E., and Lohrmann, R. 1973. Further studies of urea-catalyzed phosphorylation reactions. J Mol Evol 2:231-234.

Peyser, J.R. and Ferris, J.P. 2001. The rates of hydrolysis of thymidyl$3^{\prime}, 5^{\prime}$-thymidine-H-phosphonate: the possible role of nucleic acids linked by diesters of phosphorous acid in the origins of life. Orig Life Evol Biosph 31:363-380.

Pitsch, S., Eschenmoser, A., Gedulin, B., Hui, S., and Arrhenius, G. 1995. Mineral induced formation of sugar phosphates. Orig Life Evol Biosph 25:297-334.

Pitsch, S., Wendeborn, S., Krishnamurthy, R., Holzner, A., Minton, M., Bolli, M., et al. 2003. Pentopyranosyl oligonucleotide systems, 9th 
communication. The beta-D-ribopyranosyl-(4'-2')-oligonucleotide system ("Pyranosyl-RNA"): synthesis and resume of base-pairing properties. Helv Chim Acta 86:4270-4363.

Prabahar, K.J. and Ferris, J.P. 1997. Adenine derivatives as phosphateactivating groups for the regioselective formation of $3^{\prime}, 5^{\prime}$-linked oligoadenylates on montmorillonite: possible phosphate-activating groups for the prebiotic synthesis of RNA. JAm Chem Soc 119:43304337.

Prudent, J.R., Uno, T., and Schultz, P.G. 1994. Expanding the scope of RNA catalysis. Science 264:1924-1927.

Puglisi, J.D. and Williamson, J.R. 1999. RNA interaction with small ligands and peptides. In The RNA World, 2nd ed., pp. 403-425. Gesteland, R.F., Cech, T.R., and Atkins, J.F., Eds., Cold Spring Harbor: Cold Spring Harbor Laboratory Press.

Reid, C. and Orgel, L.E. 1967. Synthesis of sugars in potentially prebiotic conditions. Nature 216:455.

Reimann, R. and Zubay, G. 1999. Nucleoside phosphorylation: a feasible step in the prebiotic pathway to RNA. Orig Life Evol Biosph 29:229-247.

Ricardo, A., Carrigan, M.A., Olcott, A.N., and Benner, S.A. 2004. Borate minerals stabilize ribose. Science 303:196.

Robertson, M.P. and Miller, S.L. 1995a. An efficient prebiotic synthesis of cytosine and uracil. Nature 375:772-774.

Robertson, M.P. and Miller, S.L. 1995b. Correction. an Efficient Prebiotic Synthesis of Cytosine and Uracil. Nature 377:257.

Rohatgi, R., Bartel, D.P., and Szostak, J.W. 1996a. Kinetic and mechanistic analysis of nonenzymatic, template-directed oligoribonucleotide ligation. J Am Chem Soc 118:3332-3339.

Rohatgi, R., Bartel, D.P., and Szostak, J.W. 1996b. Nonenzymatic, template-directed ligation of oligoribonucleotides is highly regioselective for the formation of $3^{\prime}-5^{\prime}$ phosphodiester bonds. J Am Chem Soc 118:3340-3344.

Saffhill, R. 1970. Selective phosphorylation of the cis-2', $3^{\prime}$-diol of unprotected ribonucleosides with trimetaphosphate in aqueous solution. J Org Chem 35:2881-2883.

Saladino, R., Crestini, C., Costanzo, G., Negri, R., and Di Mauro, E. 2001. A possible prebiotic synthesis of purine, adenine, cytosine, and $4(3 \mathrm{H})$-pyrimidinone from formamide: implications for the origin of life. Bioorg Med Chem 9:1249-1253.

Sanchez, R., Ferris, J.P., and Orgel, L.E. 1966a. Conditions for purine synthesis: did prebiotic synthesis occur at low temperatures? Science 153:72-73.

Sanchez, R.A., Ferris, J.P., and Orgel, L.E. 1966b. Cyanoacetylene in prebiotic synthesis. Science 154:784-785.

Sanchez, R.A., Ferris, J.P., and Orgel, L.E. 1967. Studies in prebiotic synthesis. II. Synthesis of purine precursors and amino acids from aqueous hydrogen cyanide. J Mol Biol 30:223-253.

Sanchez, R.A., Ferris, J.P., and Orgel, L.E. 1968. Studies in prebiotic synthesis. IV. Conversion of 4-aminoimidazole-5-carbonitrile derivatives to purines. J Mol Biol 38:121-128.

Sanchez, R.A. and Orgel, L.E. 1970. Studies in prebiotic synthesis. V. Synthesis and photoanomerization of pyrimidine nucleosides. $\mathrm{J} \mathrm{Mol}$ Biol 47:531-543.

Sawai, H. 1976. Catalysis of internucleotide bond formation by divalent metal ions. J Am Chem Soc 98:7037-7039.

Sawai, H., Higa, K., and Kuroda, K. 1992. Synthesis of cyclic and acyclic oligocytidylates by uranyl catalysis in aqueous solution. Chem Soc Perkin Trans 1:505-508.
Sawai, H., Karoda, K., and Hojo, T. 1989. Uranyl ion as a highly effective catalyst for internucleotide bond formation. Bull Chem Soc Jpn 62:2018-2023.

Sawai, H. and Orgel, L.E. 1975. Oligonucleotide synthesis catalyzed by the $\mathrm{Zn}^{2+}$ ion. J Am Chem Soc 97:3532-3533.

Schmidt, J.G., Christensen, L., Nielsen, P.E., and Orgel, L.E. 1997. Information transfer from DNA to peptide nucleic acids by templatedirected syntheses. Nucleic Acids Res 25:4792-4796.

Schoning, K., Scholz, P., Guntha, S., Wu, X., Krishnamurthy, R., and Eschenmoser, A. 2000. Chemical etiology of nucleic acid structure: the alpha-threofuranosyl- $\left(3^{\prime} \rightarrow 2^{\prime}\right)$ oligonucleotide system. Science 290: $1347-1351$.

Schwartz, A.W. 1969. Specific phosphorylation of the 2'- and $3^{\prime}$ positions in ribonucleotides. J Am Chem Soc 23:1393.

Schwartz, A.W. 1997. Prebiotic phosphorus chemistry reconsidered. Orig Life Evol Biosph 27:505-512.

Schwartz, A.W., Joosten, H., and Voet, A.B. 1982. Prebiotic adenine synthesis via HCN oligomerization in ice. Biosystems 15:191-193.

Schwartz, A.W. and Orgel, L.E. 1984. Template-directed polynucleotide synthesis on mineral surfaces. J Mol Evol 21:299300 .

Shabarova, Z.A. 1988. Chemical development in the design of oligonucleotide probes for binding to DNA and RNA. Biochimie 70:13231334.

Shapiro, R. 1999. Prebiotic cytosine synthesis: a critical analysis and implications for the origin of life. Proc Natl Acad Sci USA 96:43964401.

Shapiro, R. 2002. Comments on 'concentration by evaporation and the prebiotic synthesis of cytosine.' Orig Life Evol Biosph 32:275278.

Sleeper, H.L. and Orgel, L.E. 1979. The catalysis of nucleotide polymerization by compounds of divalent lead. J Mol Evol 12:357364.

Socha, R., Weiss, A.H., and Sakharov, M.M. 1980. Autocatalysis in the formose reaction. React Kinet Catal Lett 14:119-124.

Steitz, T.A. and Moore, P.B. 2003. RNA, the first macromolecular catalyst: the ribosome is a ribozyme. Trends Biochem Sci 28:411-418.

Sulston, J., Lohrmann, R., Orgel, L.E., and Miles, H.T. 1968a. Nonenzymatic synthesis of oligoadenylates on a polyuridylic acid template. Proc Natl Acad Sci USA 59:726-733.

Sulston, J., Lohrmann, R., Orgel, L.E., and Miles, H.T. 1968b. Specificity of oligonucleotide synthesis directed by polyuridylic acid. Proc Natl Acad Sci USA 60:409-415.

Sulston, J., Lohrmann, R., Orgel, L.E., Schneider-Bernloehr, H., Weimann, B.J., and Miles, H.T. 1969. Non-enzymic oligonucleotide synthesis on a polycytidylate template. J Mol Biol 40:227-234.

Tapiero, C.M. and Nagyvary, J. 1971. Prebiotic formation of cytidine nucleotides. Nature 231:42-43.

Tsuhako, M., Fujimoto, M., Ohashi, S.A., Nariai, H., and Motooka, I. 1984. Phosphorylation of nucleosides with sodium cyclo-triphosphate. Bull Chem Soc Japan 57:3274-3280.

Unrau, P.J. and Bartel, D.P. 1998. RNA-catalysed nucleotide synthesis. Nature 395:260-263.

Voet, A.B. and Schwartz, A.W. 1983. Prebiotic adenine synthesis from $\mathrm{HCN}$-evidence for a newly discovered major pathway. Biorg Chem 12:8-17.

Wachtershauser, G. 1988. Before enzymes and templates: theory of surface metabolism. Microbiol Rev 52:452-484. 
Wakamatsu, H., Yamada, Y., Saito, T., Kumashiro, I., and Takenishi, T. 1966. Synthesis of adenine by oligomerization of hydrogen cyanide. J Org Chem 31:2035-2036.

Walde, P., Wick, R., Fresta, M., Mangone, A., and Luisi, P.L. 1994. Autopoietic self-reproduction of fatty acid vesicles. J Am Chem Soc 116:11649-11654.

Wang, K.J. and Ferris, J.P. 2001. Effect of inhibitors on the montmorillonite clay-catalyzed formation of RNA: studies on the reaction pathway. Orig Life Evol Biosph 31:381-402.

White, H.B., 3rd. 1976. Coenzymes as fossils of an earlier metabolic state. J Mol Evol 7:101-104.

Wilson, D.S. and Szostak, J.W. 1999. In vitro selection of functional nucleic acids. Annu Rev Biochem 68:611-647.

Woese, C. 1967. The Genetic Code, the Molecular Basis for Genetic Expression. New York: Harper and Row.

Wohler, F. 1828. On the artificial production of urea. Annalen der physik und chemie 88:253-256.

Wu, T. and Orgel, L.E. 1992a. Nonenzymatic template-directed synthesis on oligodeoxycytidylate sequences in hairpin oligonucleotides. $J$ Am Chem Soc 114:317-322.

Wu, T. and Orgel, L.E. 1992b. Nonenzymatic template-directed synthesis on hairpin oligonucleotides. 2. Templates containing cytidine and guanosine residues. J Am Chem Soc 114:5496-5501.
Wu, T. and Orgel, L.E. 1992c. Nonenzymatic template-directed synthesis on hairpin oligonucleotides. 3. Incorporation of adenosine and uridine residues. J Am Chem Soc 114:7963-7969.

Yamagata, Y. 1999. Prebiotic formation of ADP and ATP from AMP, calcium phosphates and cyanate in aqueous solution. Orig Life Evol Biosph 29:511-520.

Yamagata, Y., Inoue, H., and Inomata, K. 1995. Specific effect of magnesium ion on 2',3'-cyclic AMP synthesis from adenosine and trimeta phosphate in aqueous solution. Orig Life Evol Biosph 25:47-52.

Yamagata, Y., Watanabe, H., Saitoh, M., and Namba, T. 1991. Volcanic production of polyphosphates and its relevance to prebiotic evolution. Nature 352:516-519.

Zielinski, M., Kozlov, I.A., and Orgel, L.E. 2000. A comparison of RNA with DNA in template-directed synthesis. Helv Chim Acta 83:16781684.

Zolotov, M.Y., Seewald, J.S., and McCallum, T.M. 2001. Experimental investigation of aqueous carbon monoxide reactivity under hydrothermal condition. In Eleventh Annual V. M. Goldschmidt Conference. Hot Springs, VA.

Zubay, G. 1998. Studies on the lead-catalyzed synthesis of aldopentoses. Orig Life Evol Biosph 28:13-26.

Zubay, G. and Mui, T. 2001. Prebiotic synthesis of nucleotides. Orig Life Evol Biosph 31:87-102. 